\title{
Propagation Mechanisms for Government Spending Shocks: A Bayesian Comparison*
}

\author{
Anna Kormilitsina ${ }^{\dagger}$ \\ Southern Methodist University \\ Sarah Zubairy $\ddagger$ \\ Texas A\&M University
}

January 5, 2015

\begin{abstract}
The inability of a simple real business cycle model to predict a rise in consumption in response to increased government expenditures observed in many empirical studies, has stimulated the development of alternative theories of government spending shocks. Using the Bayesian approach, we evaluate the quantitative performance of five extant models, and find that neither of the considered transmission mechanisms for government spending helps improve the fit of the baseline model. Moreover, all estimated models fail to predict a rise in consumption in response to increased government spending.
\end{abstract}

JEL Classification: C11, E32, E62

Keywords: government spending shock, Bayesian comparison, transmission mechanism, deep habits, rule of thumb,

${ }^{*}$ We would like to thank Chetan Dave, Stephanie Schmitt-Grohe and conference participants at 2012 Midwest Macro Meetings, 2013 Canadian Economic Association Meetings and 2013 SNDE conference for comments and suggestions. All errors are our own.

${ }^{\dagger}$ Corresponding author. E-mail: annak@smu.edu

†E-mail: szubairy@tamu.edu 


\section{Introduction}

Recently, there has been a rising interest in modeling government spending and its effects on the economy. This growing research has resulted in a variety of models with government spending shocks, however the question remains as to which model is most appropriate for empirical analysis. In this paper, within a medium-scale dynamic stochastic general equilibrium (DSGE) environment, we quantitatively investigate several propagation mechanisms for government spending shocks proposed in the literature.

All the models we include in this investigation were developed in an attempt to resolve the inconsistency between empirical and theoretical literature predictions about the co-movement between public and private expenditures conditional on a government spending shock. The response of consumption to a government spending shock is subject to a lively debate, and of great importance in studying the stimulative effects of increased government spending. While many empirical studies, using various methods of identifying government spending shocks, find evidence of a government spending increase boosting private consumption (see Blanchard and Perotti (2002), Fatas and Mihov (2001), Mountford and Uhlig (2009) and Fisher and Peters (2010)), traditional RBC models fail to generate this positive correlation between private and public consumption. ${ }^{1}$ The main reason for this is that an increase in government spending generates a dominating negative wealth effect on consumers, which inevitably leads to a fall in private consumption.

Different modifications to a standard model have been proposed in the literature. For example, Ravn, Schmitt-Grohé, and Uribe (2006) argue that positive response of consumption to a government spending shock can be achieved if firm markups of prices over marginal costs are counter-cyclical with the economic activity. In this situation, since rising government spending results in an expansion of aggregate demand, the markups fall and as a consequence, the labor demand rises. With the sufficient expansion of the labor demand and hours in equilibrium, wages may consequently go up to ensure a rise in consumption. Countercyclical movements in markups can generally be achieved by introducing price stickiness. However, Linnemann and Schabert (2003) demonstrate that price stickiness alone is not sufficient to predict a rise in consumption in response to increasing government expenditures. Ravn, Schmitt-Grohé, and Uribe (2006) use the notion of "deep habits" in preferences for consumption to generate endogenous countercyclical markups. The notion of deep habits applies when consumers form habits at individual varieties of goods, rather than at the aggregate level, as is the case in more standard models of "superficial" habit formation. They

\footnotetext{
${ }^{1}$ The response of consumption to a government spending shock is not uncontroversial, with the empirical literature predicting positive, insignificant and negative responses to government spending shock. See Perotti (2008) and Ramey (2011) for a discussion.
} 
show that the deep habits mechanism allows to generate large enough movements in markups to guarantee a rise in consumption even in the absence of price stickiness.

An alternative way to model positive correlation between public and private consumption is offered by Galí, Lopez-Salido, and Vallés (2007). The authors introduce households who do not make optimizing decisions, and may therefore increase consumption in response to a rise in government spending. Following the so-called "rule-of-thumb", these households consume their entire disposable income in each period. If an increase in consumption of the rule-of-thumb consumers is large enough, the aggregate consumption may increase after rising government spending.

Besides deep habit formation and rule-of-thumb households, other modifications of a standard RBC framework have been used to resolve the problem of co-movement between private and public consumption. Firstly, Linnemann and Schabert (2004) and Bouakez and Rebei (2007) consider an environment where the household directly benefits from government spending through increased utility. They show that if the elasticity of substitution between public and private spending is sufficiently low, then an increase in government spending raises the marginal utility of consumption, making private consumption more attractive for households. If this effect dominates the negative wealth effect of public spending, the positive correlation of private and public consumption may be observed in response to a public spending shock. Ganelli and Tervala (2009) arrive at the same conclusion in a model where public and private consumption are complements.

Secondly, Baxter and King (1993), Ambler and Paquet (1996), and Linnemann and Schabert (2006) model government spending as enhancing productivity of firms. When higher government spending rises productivity, it increases the scale of production and as a result consumer welfare, which provides a possibility for consumption to rise in response to higher government spending. Linnemann and Schabert (2006) show that even if the impact of government expenditures on production is small, government expenditures can cause a rise in private consumption if the government share is not too large and public finance does not solely rely on distortionary taxation.

Lastly, Linnemann (2006) and Monacelli and Perotti (2008) claim that the positive effect of government spending on consumption may be obtained by choosing a specific form of the utility function. In particular, using a simple real business cycle framework, Linnemann (2006) demonstrates that the necessary requirement for the positive consumption response to the government spending shock is a non-separable utility and complementarity between consumption and leisure. At the same time, Monacelli and Perotti (2008) emphasize that the wealth effect on labor supply is important in determining the effect of government spending on consumption. For utility functions where the wealth effect on labor supply is absent, using 
a DSGE setting with nominal rigidities, they show that consumption increases in response to a government spending shock, while a drop in consumption is observed in a model where the wealth effect on labor supply is large.

In this paper, the focus is on the quantitative comparison of five models - the deep habits model, the model with rule-of-thumb consumers, the model where government spending influences individual preferences directly, the model with productive government expenditures, and finally the baseline model that does not rely on any of these mechanisms. For the baseline model, we adopt a non-separable utility function, which allows for the possibility of either a positive or negative response of consumption to the government spending shock depending on the estimated size of the wealth effect on labor supply. Because we want to make all models comparable, we use the same utility specification in the other four models as well. While models incorporating these distinct mechanisms have been estimated in separate studies, ${ }^{2}$ they normally have varying in model assumptions and data sets, which makes it difficult or impossible to compare the models and their transmission mechanisms. For proper model comparison, we embed the transmission mechanisms into identical frameworks, and estimate them using identical data sets and prior distributions for all common parameters in the models.

We use the Bayesian approach in order to evaluate the relative quantitative performance of these models. While the models have been, in some studies, estimated by matching impulse responses of the government spending shock, we intentionally choose to rely on the full information Bayesian estimation approach. This choice is motivated in part by the controversy that still exists about the response of consumption to a spending shock. It has been established that structural VAR models that utilize timing restrictions or Cholesky decomposition for shock identification generally predict positive co-movement of private and public consumption (see Blanchard and Perotti (2002) or Fatas and Mihov (2001)), while the opposite result is obtained in models where the shock is identified using the narrative approach (see Ramey (2011)). Therefore, estimating a model by matching model impulse responses to the data is subject to conditioning on the shock identification procedure. While it may still be useful as an exercise to verify the ability of a model to produce the positive co-movement, such an estimation strategy does not contribute to the dispute regarding the qualitative response of consumption. One goal of this paper is to find out whether, when taken to match the data unconditionally, the proposed transmission mechanisms predict

\footnotetext{
${ }^{2}$ For instance rule-of-thumb consumers have been explored by a series of papers featuring an estimated medium scale DSGE model, e.g Forni, Monteforte, and Sessa (2009), Coenen and Straub (2005) and Cogan, Cwik, Taylor, and Wieland (2010) among many others. Zubairy (2010) explores deep habit formation, Traum and Yang (2010) incorporate productive government capital and Bouakez and Rebei (2007) consider government spending in the utility function in an estimated DSGE model.
} 
positive or negative response of private consumption to the government spending shock.

The main result of the paper is that the baseline model outperforms all the other models in fitting the data. Therefore, we conclude that the inclusion of all the different transmission mechanisms for government spending considered does not help improve the fit of the baseline model, and in some cases even worsens the overall fit to the data. Interestingly, we find that all five of the estimated models consistently generate a negative response of consumption to the government spending shock, even though all these model were essentially motivated with mechanisms to generate a positive response of consumption. In addition, while the consumption effect of the government spending shock is very similar across the estimated models, we find that the resulting output multipliers on impact are either slightly above and below 1 , depending on the model specifications.

The paper proceeds as follows. We describe the general framework and model specifics

in Section 2. Section 3 offers the strategy for estimation and model analysis. Section 4 discusses estimation results and finally, Section 5 concludes.

\section{Models of Government Spending}

In this section, we describe the models with distinct propagation mechanisms for government spending shocks used in the quantitative analysis. All these models have some features in common. In particular, each model is introduces three types of agents: households, firms and a policy authority. Although exact specification may be different across models, we assume household's preferences are influenced by consumption habits. We make the same assumptions regarding investment adjustment costs, and endogenous depreciation, which is tied to the degree of capital utilization. The role of monetary policy is motivated by nominal price and wage rigidities, while monetary policy is described by a standard Taylor-type rule. In addition to the government spending shock, there are seven other sources of uncertainty. They are the neutral and investment specific technology shocks, preference shock, wage and price markup shocks, tax shock and monetary policy shock. We model the economy as evolving along the balanced growth path, with the long-run trend for consumption, output, wages different from the long-run trend in capital and investment.

The specific models of government spending extend this set up in the following way: the first model incorporates deep habit formation over consumption of private and public goods. The second model introduces a share of the households being rule-of-thumb consumers. The other two models assume that government spending enhances household utility function the production technology, respectively. Finally, the baseline model does not have any of these specific features, however, the positive response of consumption is possible because of the 
wealth effect on labor supply, associated with household utility function that is non-separable between consumption and leisure.

\subsection{Main Framework}

The economy is populated by a continuum of infinitely-lived households. Each household participates in the following activities. It consumes, supplies differentiated labor services to the labor packer, accumulates capital by means of investing, rents capital services to firms, pays taxes and receives dividends from ownership in firms.

\subsubsection{Households}

Each household derives utility from a consumption measure $X_{t}$, the exact definition of which differs across the three models, and homogenous labor $h_{t}$. The life-time expected utility of households is defined as

$$
E_{0} \sum_{t=0}^{\infty} \beta^{t} d_{t} U\left(X_{t}, h_{t}\right)
$$

where $E_{0}$ denotes expectations based on period zero information set, $\beta$ is the discount factor, and $d_{t}$ is the preference shock, evolving according to an $A R(1)$ process:

$$
\log \left(\frac{d_{t+1}}{d}\right)=\rho_{d} \log \left(\frac{d_{t}}{d}\right)+\epsilon_{t+1}^{d}
$$

where $0<\rho_{d}<1$, and $\epsilon_{t}^{d} \sim i . i . d .\left(0, \sigma_{d}^{2}\right)$, with $\sigma_{d}>0$, is the preference shock. The intratemporal utility function follows King, Plosser, and Rebelo (1988) in that it is nonseparable in leisure and consumption and consistent with long-run balanced growth:

$$
U\left(X_{t}, h_{t}\right) \equiv \frac{X_{t}^{1-\sigma}}{1-\sigma}\left(1-h_{t}\right)^{\zeta}
$$

where the inverse of $\sigma>0$ is the inverse of the intertemporal elasticity of substitution in consumption, and $\zeta>0 .^{3}$

Homogenous labor $h_{t}$ is a Dixit-Stiglitz aggregate of differentiated labor services $h_{t}^{j}$, for

\footnotetext{
${ }^{3}$ This utility function assumes the existence of wealth effect from the government spending shock on labor supply, as opposed to the GHH type preferences, where this wealth effect is absent. Monacelli and Perotti (2008) show that absent the wealth effect, a standard new-Keynesian model with price rigidities will produce a positive response of consumption to a government spending shock. We choose to avoid the possibility of automatically generating the positive response without eliminating this possibility, allowing the estimation procedure to determine the size of the wealth effect.
} 
$j \in[0,1]$ supplied by households to a labor packer:

$$
h_{t}=\left(\int_{0}^{1}\left(h_{t}^{j}\right)^{1-\frac{1}{\eta_{t}^{w}}} d j\right)^{\frac{1}{1-\frac{1}{\eta_{t}^{w}}}} .
$$

Here, $\eta_{t}^{w}$ is the elasticity of substitution across different types of labor, and the upper script $j$ helps to distinguish between different types of labor. As in Smets and Wouters (2007), the wage markup is modeled as an ARMA $(1,1)$ process,

$$
\log \left(\frac{\eta_{t+1}^{w}}{\eta^{w}}\right)=\rho_{w} \log \left(\frac{\eta_{t}^{w}}{\eta^{w}}\right)+\epsilon_{t+1}^{w}-\mu_{w} \epsilon_{t}^{w},
$$

where $\eta_{w}>1,0<\rho_{w}<1$, and $\epsilon_{t}^{w} \sim$ i.i.d. $\left(0, \sigma_{w}^{2}\right)$, with $\sigma_{w}>0$ is the wage markup shock.

The homogenous labor $h_{t}$ is supplied to firms at a real rate $W_{t}$. Households possess monopolistic power over their wages, and have the ability to set the labor specific wage rate; however, they are required to satisfy the demand for labor at this wage rate. Changes in the wage rate are subject to quadratic adjustment cost, determined as

$$
\Psi\left(\frac{W_{t}^{j}}{W_{t-1}^{j}}\right)=\frac{\alpha_{w}}{2}\left(\frac{W_{t}^{j}}{W_{t-1}^{j}} \pi_{t}-\mu_{z^{*}} \pi\right)^{2},
$$

per (real) dollar of the wage bill. In this formula, $\alpha_{w}>0$ is the wage adjustment cost parameter, $W_{t}^{j}$ is the individual real wage rate, $\pi_{t}$ and $\pi$ are the inflation rate at a date $t$ and along the balanced growth path, respectively, and $\mu_{z^{*}}$ is the rate of growth of the economy (output, consumption, and wages) along the balances growth path.

The households own physical capital, $K_{t}$. Capital is accumulated through the process of investing, and the total stock of capital depreciates at a variable rate depending on how intensively it is used. Moreover, investment adjustment is costly, with the capital loss of $S(\cdot)$ per unit of investment. The dynamics of capital is therefore:

$$
K_{t+1}=\left(1-\delta\left(u_{t}\right)\right) K_{t}+I_{t}\left(1-\mathcal{S}\left(\frac{I_{t}}{I_{t-1}}\right)\right)
$$

where $u_{t}$ determines the intensity of capital utilization as a fraction of capital being used in production, and $\delta\left(u_{t}\right)$ is the depreciation function, parameterized as follows:

$$
\delta\left(u_{t}\right)=\delta_{0}+\delta_{1}\left(u_{t}-u\right)+\frac{\delta_{2}}{2}\left(u_{t}-u\right)^{2}
$$

where $\delta_{0}, \delta_{1}, \delta_{2} \geq 0$, and $u$ is the steady state rate of capital utilization, In Equation (4), the 
cost of investment $S(\cdot)$ is the quadratic function:

$$
\mathcal{S}\left(\frac{I_{t}}{I_{t-1}}\right)=\frac{\kappa}{2}\left(\frac{I_{t}}{I_{t-1}}-\mu_{I}\right)^{2}
$$

where $\kappa>0$, and $\mu_{I}$ is the steady-state growth rate of capital and investment.

Following Fisher (2003), investment goods $I_{t}$ are obtained from consumption using a stochastic linear technology, according to which at each date $t$, one unit of consumption can produce $\Upsilon_{t}$ units of investment. We call $\Upsilon_{t}$ the investment specific technology. Denoting $\mu_{\Upsilon, t} \equiv \Upsilon_{t} / \Upsilon_{t-1}$, the gross growth rate of $\Upsilon_{t}$, the dynamics for the growth rate of the investment specific technology is

$$
\log \left(\frac{\mu_{\Upsilon, t+1}}{\mu_{\Upsilon}}\right)=\rho_{\Upsilon} \log \left(\frac{\mu_{\Upsilon, t}}{\mu_{\Upsilon}}\right)+\epsilon_{t+1}^{\Upsilon},
$$

where $\epsilon_{t}^{\Upsilon} \sim$ i.i.d. $\left(0, \sigma_{\Upsilon}^{2}\right)$, with $\sigma_{\Upsilon}>0$, and $\mu_{\Upsilon}$ is the growth rate of the investment specific technology along the balanced growth path.

Capital services $u_{t} K_{t}$ are rented out to firms at a real rental rate $R_{t}^{k}$. Households own shares in firms, and receive dividends with the real value $\Phi_{t}$. They pay a distortionary income tax, at the rate $\tau_{t}$, and receive lump-sum transfers in the amount $T r_{t}$ in terms of consumption. Complete set of one-period state-contingent assets, as well as the risk-free government bonds are traded in financial markets. If households have access to financial markets, ${ }^{4}$ then the budget constraint can be written as ${ }^{5}$

$$
\begin{aligned}
E_{t} r_{t, t+1} L_{t+1}+ & C_{t}+\Upsilon_{t}^{-1} I_{t}+\frac{B_{t+1}}{R_{t}} \\
& =\frac{L_{t}}{\pi_{t}}+\left(1-\tau_{t}\right) R_{t}^{k} u_{t} K_{t}+\int\left(1-\tau_{t}-\Psi\left(\frac{W_{t}^{j}}{W_{t-1}^{j}}\right)\right) W_{t}^{j} h_{t}^{j} d j+\Phi_{t}+\frac{B_{t}}{\pi_{t}}+\operatorname{Tr}_{t},
\end{aligned}
$$

where $L_{t}$ is the payoff in period $t$ of state-contingent securities traded in period $t-1, r_{t, t+1}$ is the price of a state contingent security traded at date $t$ for a claim on consumption delivered in period $t+1, C_{t}$ is real consumption, $\tau_{t}$ is the income tax rate, and $B_{t}$ is the real value of non-state contingent government bonds in possession of households. The new bonds are purchased at a price $1 / R_{t}$.

\footnotetext{
${ }^{4}$ This is the case in all models except for the model with rule-of-thumb consumers.

${ }^{5}$ To simplify notation, we omit the household specific superscript $j$ when it is possible.
} 


\subsubsection{Firms}

A continuum of monopolistically competitive firms of measure 1 produce differentiated intermediate goods. For production, each firm uses capital and labor services, $u_{t} K_{t}$ and $h_{t}$ according to the following technology

$$
F\left(u_{t} K_{t}, Z_{t} h_{t}\right) \leq q_{t}\left(u_{t} K_{t}\right)^{\theta}\left(Z_{t} h_{t}\right)^{1-\theta}-\vartheta Z_{t}^{*}
$$

where $0<\theta<1$, variable $q_{t}$ is model specific, introduced in Section 2.2, $Z_{t}^{*} \vartheta$ represents the fixed costs of operating a firm in each period, and $Z_{t}$ is the stochastic labor-augmenting productivity process, with the growth of $Z_{t}, \mu_{z, t} \equiv Z_{t} / Z_{t-1}$, evolving according to

$$
\log \left(\frac{\mu_{z, t+1}}{\mu_{z}}\right)=\rho_{z} \log \left(\frac{\mu_{z, t}}{\mu_{z}}\right)+\epsilon_{t+1}^{z},
$$

where $\mu_{z}$ is the growth rate along the balanced growth path, $0<\rho_{z}<1$, and $\epsilon_{t}^{z} \sim$ i.i.d. $\left(0, \sigma_{z}^{2}\right)$, with $\sigma_{z}>0$.

Each firm $i \in[0,1]$ maximizes the present discounted value of dividend payments, given by

$$
E_{t} \sum_{s=0}^{\infty} r_{t, t+s} P_{t+s}^{i} \Phi_{t+s}^{i}
$$

where $r_{t, t+s} \equiv \prod_{k=1}^{s} r_{t+k-1, t+k}$, for $s \geq 1$, with $r_{t, t} \equiv 1$, and period $t$ dividend payments are

$$
\Phi_{t}^{i}=\frac{P_{t}^{i}}{P_{t}} a_{t}^{i}-R_{t}^{k} u_{t}^{i} K_{t}-W_{t} h_{t}^{i}-\Omega\left(\frac{P_{t}^{i}}{P_{t-1}^{i}}\right)
$$

where $a_{t}^{i}$ is the demand for the firm's output, $\Omega(\cdot)$ is the cost of price changes, following Rotemberg (1982). We assume that this cost is quadratic and proportional to the stochastic trend $Z_{t}^{*}$ :

$$
\Omega\left(\frac{P_{t}^{i}}{P_{t-1}^{i}}\right)=\frac{\alpha_{p} Z_{t}^{*}}{2}\left(\frac{P_{t}^{i}}{P_{t-1}^{i}}-\pi\right)^{2},
$$

with $\alpha_{p}>0$, denoting the degree of price stickiness. Monopolistically competitive firms must satisfy their demands at the posted price.

In all models except the one with deep habits, the good intended for final consumption is the aggregate of differentiated goods produced by monopolistically competitive firms using a Dixit-Stiglitz technology:

$$
\left(\int_{0}^{1}\left(Y_{t}^{i}\right)^{1-\frac{1}{\eta_{p, t}}} d i\right)^{\frac{1}{1-\frac{1}{\eta_{p, t}}}}
$$

where $\eta_{p, t}$ is the elasticity of substitution between individual good varieties. which is assumed 
to follow an ARMA $(1,1)$ process,

$$
\log \left(\frac{\eta_{t+1}^{p}}{\eta^{p}}\right)=\rho_{p} \log \left(\frac{\eta_{t}^{p}}{\eta^{p}}\right)+\epsilon_{t+1}^{p}-\mu_{p} \epsilon_{t}^{p}
$$

where $0<\rho_{p}<1$, and $\epsilon_{t}^{p} \sim i . i . d .\left(0, \sigma_{p}^{2}\right)$, with $\sigma_{p}>0$, is the price markup shock. ${ }^{6}$

\subsubsection{Fiscal and monetary policy}

The fiscal authority levies taxes, provides lump-sum transfers and develops public projects with real cost of $G_{t}$. We assume that each period, the government satisfies a balanced budget. To ensure the model has a well-defined balanced growth path, we assume that government expenditures $G_{t}$ evolve along the same stochastic trend as output and consumptions. With this purpose, we assume the ratio $\varsigma_{t}^{g}=G_{t} / Y_{t-1}$ is an $\operatorname{AR}(1)$ process: ${ }^{7}$

$$
\log \left(\frac{\varsigma_{t+1}^{g}}{\varsigma^{g}}\right)=\rho_{g} \log \left(\frac{\varsigma_{t}^{g}}{\varsigma^{g}}\right)+\epsilon_{t+1}^{g}
$$

where $0<\rho^{g}<1$, and $\epsilon_{t}^{g} \sim$ i.i.d. $\left(0, \sigma_{g}^{2}\right)$, with $\sigma_{g}>0$, is the government spending shock.

Households face distortionary taxes on their income to finance government spending, and the income tax rate $\tau_{t}$ evolves according to the following process:

$$
\log \left(\frac{\tau_{t}}{\tau}\right)=\alpha_{\tau} \log \left(\frac{\tau_{t-1}}{\tau}\right)+\alpha_{\tau, y} \log \left(Y_{t-1} / \tilde{Y}_{t-1}\right)+\epsilon_{t}^{\tau}
$$

where $0<\alpha_{\tau}<1$, and $\epsilon_{t}^{\tau} \sim$ i.i.d. $\left(0, \sigma_{\tau}^{2}\right)$, with $\sigma_{\tau}>0$, is the tax shock. $\tilde{Y}_{t}=Z_{t}^{*} y$, where $y$ is the (detrended) steady state level of output. Parameter $\alpha_{\tau, y}$ measures the response of the tax rate to economic conditions measured by the output gap $Y_{t} / Y$, which allows to capture automatic stabilizer effects. ${ }^{8}$

We assume that monetary policy is described by a generalized Taylor type rule with the interest rate smoothing and response to inflation and output growth, as follows:

$$
\log \left(\frac{R_{t}}{R}\right)=\alpha_{R} \log \left(\frac{R_{t-1}}{R}\right)+\alpha_{\pi} \log \left(\frac{\pi_{t}}{\pi}\right)+\alpha_{Y} \log \left(\frac{Y_{t}}{Y_{t-1} \mu_{z^{*}}}\right)+\epsilon_{t}^{r}
$$

\footnotetext{
${ }^{6}$ The price markup shock will take the same form for all models under consideration.

${ }^{7}$ Such modeling assumption is motivated by the fact that planned government expenditures are decided upon prior to the year of implementation, and therefore current public expenditures are predetermined with respect to current output. To implement this idea, we define $\varsigma_{t}^{g}$ as the ratio of $G_{t}$ and the previous, rather than current period output, $Y_{t-1}$. We find that this approach to modeling government spending shock improves the marginal likelihood of all models. Alternatively, within-period timing restrictions could be imposed, as in Kormilitsina (2013).

${ }^{8}$ The consequences of different methods of financing, including distortionary taxes are emphasized by Leeper, Plante, and Traum (2010).
} 
where $Y_{t}$ is aggregate real output, $\alpha_{R}, \alpha_{\pi}, \alpha_{Y}$ are Taylor rule parameters, and $\epsilon_{t}^{r} \sim$ i.i.d. $\left(0, \sigma_{r}^{2}\right)$ is the monetary policy shock, with $\sigma_{r}>0$.

\subsection{Model Specific Features}

In this section, we briefly describe the five models we consider, with an emphasis on their specific features. More details on the models, including the first order and market clearing conditions, are given in the Appendix.

\subsubsection{Model with Deep Habits}

We adopt the "fully-fledged" version of the deep habits model from Ravn, Schmitt-Grohé, and Uribe (2006), and define $X_{t}$ in Equation (2) as

$$
X_{t}=\left[\int_{0}^{1}\left(C_{i, t}-b^{c} S_{i, t-1}^{c}\right)^{1-\frac{1}{\eta_{p, t}}} d i\right]^{1 /\left(1-\frac{1}{\eta_{p, t}}\right)}
$$

where index $i$ refers to a variety of differentiated goods produced by monopolistically competitive firms, $b^{c}$ is the habit formation parameter for private consumption. Note that deep habits imply habit formation at the level of the intermediate good $C_{i, t}$, and not the aggregate good $C_{t}$ that enters the utility function.

$S_{i, t}^{c}$ is the good-specific stock of habit, which evolves over time according to the law of motion,

$$
S_{i, t}^{c}=\rho^{c} S_{i, t-1}^{c}+\left(1-\rho^{c}\right) C_{i, t}
$$

with $0 \leq \rho^{c} \leq 1$.

Similar to Ravn, Schmitt-Grohé, and Uribe (2006), the government allocates spending over intermediate goods $G_{i, t}$ so as to maximize the quantity of a composite good $X_{t}^{g}$ produced with intermediate goods according to the relationship

$$
X_{t}^{g}=\left[\int_{0}^{1}\left(G_{i, t}-b^{g} S_{i, t-1}^{g}\right)^{1-\frac{1}{\eta_{p, t}}}\right]^{1 /\left(1-\frac{1}{\eta_{p, t}}\right)}
$$

where $b^{g}$ is the habits parameter for public goods, and the stock of habits $S_{i, t}^{g}$ is determined as follows

$$
S_{i, t}^{g}=\rho^{g g} S_{i, t-1}^{g}+\left(1-\rho^{g g}\right) G_{i, t}
$$

where $0 \leq \rho^{g g} \leq 1$

Parameter $q_{t}$ of the production function in Equation (7) is set to 1. 


\subsubsection{Model with Rule-of-Thumb Consumers}

As in Galí, Lopez-Salido, and Vallés (2007), we assume that only a fraction $(1-\lambda)$ of all households have access to capital markets where they can trade state-contingent bonds and accumulate capital to rent out to firms. These are known as optimizing households. Other households, the so-called rule-of-thumb consumers, do not participate in financial markets, therefore they cannot borrow or save. These households are restricted to consume their disposable labor income.

Utility of optimizing households is determined by Equation (2), where $X_{t}$ is the habit adjusted consumption,

$$
X_{t}=C_{t}^{o}-b^{c} C_{t-1}^{o},
$$

in which $b^{c}$ is the consumption habits parameter and $C_{t}^{o}$ denotes homogenous consumption of optimizing households at date $t$.

We follow Galí, Lopez-Salido, and Vallés (2007) in assuming that although optimizing households decide how much to work $\left(h_{t}^{o}\right)$ based on their utility maximization, the ruleof-thumb households follow an ad-hoc rule and work exactly the same hours $\left(h_{t}^{r}\right)$ as the optimizing consumers:

$$
h_{t}^{r}=h_{t}^{o} \equiv h_{t} .
$$

In a symmetric equilibrium, the rule-of-thumb households providing differentiated labor services, the wage rates for both types of households coincide, thus $W_{t}^{r}=W_{t}^{o}=W_{t}$ at any period $t$.

Consumption of the rule-of-thumb households is determined by their disposable income, which is determined after income taxes and wage cost adjustment as follows:

$$
C_{t}^{r}=\left(1-\tau_{t}-\Psi\left(\frac{W_{t}}{W_{t-1}}\right)\right) W_{t} h_{t}+T_{t}^{r}
$$

In this formula, $T_{t}^{r}=Z_{t}^{*} \tau^{r}$ is the lump-sum transfer that the rule-of-thumb households receive from government. We assume the detrended transfer, $\tau^{r}$, is constant. ${ }^{9}$ The lump sum tax on optimizing households is set to keep the government budget balanced.

Finally, parameter $q_{t} \equiv 1$ in Equation (7).

\footnotetext{
${ }^{9}$ The steady state value for $\tau^{r}$ is pinned down by the equality of consumption for optimizing and rule-ofthumb households.
} 


\subsubsection{Model with Government Spending in the Utility Function}

We follow Bouakez and Rebei (2007) and define $X_{t}$ in the intratemporal utility in Equation (2) as habit adjusted effective consumption,

$$
X_{t}=\tilde{C}_{t}-b^{c} \tilde{C}_{t-1}
$$

where $b^{c}>0$ is the habit formation parameter, and the effective consumption $\tilde{C}_{t}$ is the combination of private and public consumption, $C_{t}$ and $G_{t}$ :

$$
\tilde{C}_{t}=\left[\phi C_{t}^{\frac{\nu-1}{\nu}}+(1-\phi) G_{t}^{\frac{\nu-1}{\nu}}\right]^{\frac{\nu}{\nu-1}}
$$

where $0<\phi<1$ is the weight on private consumption in the effective consumption, and $\nu \geq 0$ is the elasticity of substitution between private and public spending. When $\nu \rightarrow 0$, private and public consumption are nearly perfect complements and they become substitutes for $\nu \rightarrow \infty$.

Parameter $q_{t} \equiv 1$ in the production function defined in Equation (7).

\subsubsection{Model with Productive Government Spending and the Baseline Model}

One difference between these models is that in the baseline model, $q_{t} \equiv 1$ in Equation (7), while in the model with productive government spending, we acknowledge that government actions may directly affect the production process. Similar to Baxter and King (1993), public spending enhances the production technology in Equation (7) through $q_{t}$.

For the model with productive government spending only, we distinguish between public consumption and capital. We assume that public capital improved private sector production technology by affecting $q_{t}$ in the following way

$$
q_{t}=\left(\frac{K_{t}^{g}}{Z_{t}^{*}}\right)^{\alpha_{G}}
$$

where $\alpha_{G}>0$, gives the share of government spending in the production function, and $K_{t}^{g}$ represents public capital. We assume that government investment expenditures $I_{t}^{g}$ contribute to public capital accumulation $\left(K_{t}^{g}\right)$ according to the dynamic equation

$$
K_{t+1}^{g}=\left(1-\delta\left(u_{t}\right)\right) K_{t}^{g}+I_{t}^{g}
$$

We assume both public consumption and investment are constant shares of total government 
spending $G_{t}$,

$$
\begin{gathered}
G_{t}^{c}=s^{g c} G_{t}, \\
I_{t}^{g}=\left(1-s^{g c}\right) G_{t},
\end{gathered}
$$

where $s^{g c}$ denotes the share of public consumption.

Utility in both models features standard superficial habit in consumption, therefore $X_{t}$ in Formula (2) is defined as

$$
X_{t}=C_{t}-b^{c} C_{t-1}
$$

where $b^{c}$ is the consumption habit parameter, and $C_{t}$ is consumption of final goods.

\subsection{Propagation Mechanisms of the Government Spending Shock}

According to a standard real business cycle (RBC) model, the government spending shock reduces resources of the economy generating a negative wealth effect. As a result, consumption falls, while output and labor increase. While it is widely accepted that a rise in government spending stimulates production and employment, its negative effect on consumption is puzzling in light of the majority of empirical evidence. Bilbiie (2009) demonstrates that in a simple RBC framework, there is no possibility for consumption to rise in response to rising government spending, unless the labor supply function is negatively sloped. This can be demonstrated graphically using Figure 1. The figure shows the equilibrium in the market for labor services. In the figure, the real wage rate $(w)$ is plotted along the vertical, and labor hours $(h)$ along the horizontal axis. The solid bold line in the figure represents the supply of labor before the shock, while the bold starred line is the labor demand of firms. The supply of labor is determined by,

$$
w=\frac{U_{2}(c, 1-h)}{U_{1}(c, 1-h)} .
$$

The labor demand is given by,

$$
w=m c F_{h}(u k, h),
$$

where $m c$ is the real marginal cost of firms, which is the inverse of firm's price markup over the marginal costs. In the standard RBC framework, $m c$, and $u$ equal 1 at all times and in all states of the economy. The marginal rate of substitution between consumption and leisure, $\frac{U_{2}(c, 1-h)}{U_{1}(c, 1-h)}$, is usually increasing both in consumption and labor. This property ensures that the labor supply is positively sloped, and a drop in consumption shifts the labor supply to the right, while an increase in consumption shifts the labor supply to the left.

In a standard RBC model, a rise in government spending is associated with the negative 
wealth effect, and thus it causes a drop consumption and a rise in labor supply. Note from Equation (13) that labor supply increases because when consumption drops, the same real wage rate is associated with larger supply of labor. Therefore, the equilibrium moves instantaneously from point 0 to 1 in Figure 1. If an equilibrium increase in consumption were a possibility in this model, this would cause labor supply to decrease according to Equation (13), shifting the labor supply curve to the left, with the new equilibrium at point 2. However, this scenario is not supported by equlibrium in the most standard version of the model, because this move would reduce equilibrium labor; therefore output would shrink leaving no possibility for consumption to expand. Therefore, the necessary condition for consumption to rise is that the new equilibrium supports larger employment, allowing output to expand. Such a possibility may arise in a model where labor demand increases endogenously due to rising government spending. This scenario is shown by point 3 in Figure 1. At this point labor is larger than that at point 0 and consumption increased, which means that equilibrium is supported at this point.

The introduction of imperfectly competitive goods market and price stickiness allow the labor demand to increase in the model. With price stickiness, an increase in output demand due to the rising government spending is associated with larger marginal costs and increased labor demand, since firms can not easily adjust prices. Because the marginal cost is the inverse of the firm's markup, then $m c$ and output move pro-cyclically.

It has been shown however, that price stickiness, cannot generate sufficient shifts in the labor demand curve to guarantee a rise in consumption in response to government spending shock (see Linnemann and Schabert (2003)). Therefore, additional assumptions are needed to overturn the negative wealth effect on consumption. In the model with rule of thumb consumers, this is done by introducing a fraction of non-Ricardian consumers who consume their entire disposable income in every period, following the so called "rule of thumb", or because they have no access to the financial markets. Because optimizing households still experience a drop in wealth due to a rise in public spending, the rise in total consumption can only be achieved if rule-of-thumb households increase consumption substantially, which can only happen if the wage income of optimizing households increases. The wage income rises if the wage rate or hours worked increase. Because optimizing agents demand to work more, the wage rate tends to drop. Galí, Lopez-Salido, and Vallés (2007) rely on an important assumption that labor markets are non-competitive in such a way that both types of households always work the same hours. This assumption allows the labor of rule-of-thumb households to increase when government spending rise, therefore making rising income, and consequently consumption, a possibility. Certainly, aggregate consumption in this model will only increase if the share of rule-of-thumb consumers, $\lambda$, is large enough to compensate 
for the drop in consumption of optimizing households. ${ }^{10}$

The mechanism of the deep habits follows the same route as that of nominal price rigidity, because it works by generating endogenous countercyclical markups of firms. ${ }^{11}$ The reason is that the combination of deep habits and imperfect competition results in time-varying elasticity of demand. To see this, note that in a simplified deep habits model, the demand for consumption good $i$ is given by, ${ }^{12}$

$$
C_{i, t}=\left(\frac{P_{i t}}{P_{t}}\right)^{-\eta_{p, t}}\left(C_{t}-b^{c} C_{t-1}\right)+b^{c} C_{i, t-1} .
$$

For this demand function, its price elasticity is $\eta_{p, t}\left(\frac{P_{i t}}{P_{t}}\right)^{-\eta_{p}} \frac{\left(C_{t}-b^{c} C_{t-1}\right)}{C_{i, t}} .^{13}$

Note that the price elasticity of demand is proportional to the habit adjusted aggregate consumption level, $\left(C_{t}-b^{c} C_{t-1}\right)$. Therefore, when aggregate consumption rises, the price elasticity of demand increases, and everything else equal, producers have incentives to reduce markups. By doing so, firms gain a larger share of the market to form the stock of habits and increase future profits. The resulting drop in markups raises the real marginal cost $m c$, and therefore increases the labor demand curve in the same way as in the mechanism with sticky prices. However, Ravn, Schmitt-Grohé, and Uribe (2007) show that deep habits can generate much larger movements in the markups and consequently labor demand, than price stickiness, providing a better foundation to obtain the positive response of consumption to the government spending shock. They show that the deep habits mechanism helps explain a rise in consumption even in the absence of price stickiness. ${ }^{14}$

The similar outward shift in the demand for labor leading to the new equilibrium in point 3 occurs in the model with productive government spending. In this case, however, the labor demand curve shifts out due to a rise in productivity $F_{h}$ in Equation (14), rather than the marginal cost. If the effect of government spending on labor productivity is large

\footnotetext{
${ }^{10}$ While the model considered in Galí, Lopez-Salido, and Vallés (2007) is a standard new-Keynesian framework, Furlanetto (2011) and Colciago (2011) show that the introduction of wage rigidities does not change this result qualitatively. Nominal wage rigidities mitigate the fall in the wage rate, reducing the negative wealth effect on optimizing households, and may also increase the disposable income of rule-of-thumb households. Thus, strong nominal wage stickiness may guarantee the positive correlation between public and private consumption for the rule-of-thumb households.

${ }^{11}$ This counter-cyclicality of markups has been documented in many empirical studies, such as Bils (1987), Rotemberg and Woodford (1991) and Rotemberg and Woodford (1999).

${ }^{12}$ This is the simplified demand function under the assumption of $\rho^{c}=0$. Note also that in the absence of deep habits, the demand function would be, $C_{i, t}=\left(P_{i t} / P_{t}\right)^{-\eta_{p}} C_{t}$, implying time-invariant price elasticity of $\eta_{p}$.

${ }^{13} \mathrm{~A}$ similar demand function holds for the intermediate government spending good, $G_{i t}$ and there is similar intuition behind pro-cyclicality of price elasticity in response to increased demand from government spending.

${ }^{14}$ In the case of a model that features both price stickiness and deep habits, there can be interesting interactions, as shown in Jacob (2013), where an increasing level of price stickiness mitigates the crowding-in effect on consumption in response to a spending shock.
} 
enough, which is dictated by $\alpha_{G}$ (the share of spending in the production function), the rise in consumption may be an equilibrium outcome.

Another transmission mechanism is utilized in the model where government spending directly influences utility. Linnemann and Schabert (2004) and Bouakez and Rebei (2007) notice that if private and public consumption are complements in the sense that an increase in government spending raises marginal utility of consumption, then a rise in government spending increases labor supply as shown in Figure 2. With this move, an equilibrium with rising consumption response becomes a possibility, because it is not associated with a reduction in labor supply, as shown by the new equilibrium at point 5 in the figure.

The form and calibration of the utility function by itself plays an important role in the resulting effect of government spending shock on consumption. Linnemann (2006) claims that in the RBC setting, the necessary condition for a rise in consumption is that consumption and leisure must be substitute goods in the sense that $U_{12}<0 .{ }^{15}$ Monacelli and Perotti (2008) emphasize the importance of the wealth effect on labor supply in determining the response of consumption to the government spending shock. The idea there is that the smaller is the shift of the labor supply curve as a result of the shock, the more likely the new equilibrium will move north-east of point 0 in Figure 1, raising both wages and hours. ${ }^{16}$ In the example they use, consumption rises in the economy with nominal price stickiness where preferences feature no wealth effect on labor supply, and fall if preferences are such that the wealth effect on labor supply is significant.

The models we estimate have additional features commonly used in estimated DSGE models, such as nominal wage rigidities, habit formation, investment adjustment cost, and endogenous capital utilization. While being helpful in achieving better fit with data, these features complicate intuition behind the propagation mechanism of the government spending shock. Nevertheless, we should expect that rigid wages mitigate fluctuations in income resulting from the government spending shock, therefore reducing the wealth effect on labor supply, and increasing the possibility to observe positive consumption response to the shock. Introducing superficial habits have consequences for the labor supply curve since habits will affect the wealth effect on labor supply and the resulting consumption behavior. Monacelli and Perotti (2008) demonstrate that adding habits to the simple RBC model without price stickiness helps in obtaining a positive response of consumption to a government spending shock. Endogenous capital utilization makes it possible for the labor demand to respond endogenously to rising government spending even in the standard RBC setting. Although

\footnotetext{
${ }^{15}$ With nominal rigidities, however, this does not have to be the case.

${ }^{16}$ Notice that larger wages are desirable for the positive effect of government spending on consumption, because of the consumption leisure substitution effect they create - the larger is the real wage rate the less expensive is consumption, making it more attractive for households.
} 
response of capital utilization to the shock is endogenously determined, it is expected to increase when public spending rises, affecting the demand for labor in a way similar to price stickiness. All in all, the presence of these features to some extent will have a quantitative influence on the consumption effect of government spending shocks.

\section{$3 \quad$ Estimation and Inference}

\subsection{Estimation Strategy}

The models we study can be cast in linear state space form, with a likelihood derived via a Kalman filter, which when coupled with priors on model parameters delivers posterior distribution for the parameter vector $\theta$ conditional upon the model. In doing so we keep the data employed in the observable equation constant across the models. The data $y_{t}$ is the $8 \times 1$ vector of observable variables defined as follows

$y_{t}=\left\{\Delta\left(\log \left(I_{t}\right)\right), \Delta\left(\log \left(C_{t}\right)\right), \Delta\left(\log \left(W_{t}\right)\right), \log \left(H_{t}\right), \Delta\left(\log \left(P_{Y, t}\right)\right), R_{t}, \log \left(G_{t} / Y_{t}\right), \log \left(\operatorname{Tax}_{t} / Y_{t}\right)\right\}$,

where $I_{t}$ and $C_{t}$ are real per capita investment and consumption, $W_{t}$ is real wages, $H_{t}$ are per capita hours worked, $P_{Y, t}$ is GDP deflator, therefore $\Delta\left(\log \left(P_{Y, t}\right)\right)$ measures inflation rate based on the GDP deflator. $R_{t}$ is the nominal interest rate, measured by the effective (annualized) Federal funds rate. Finally, $G_{t} / Y_{t}$ and $\operatorname{Tax}_{t} / Y_{t}$ give the government spending to GDP ratio, and the tax revenues to GDP ratio, respectively. ${ }^{17}$ All the data in vector $y_{t}$ appear in quarterly frequency, and span 1954:3 to 2010:4.

The vector of estimated model parameters is defined as

$$
\theta=\left\{\theta_{A_{i}}^{1}, \theta^{2}, \theta^{3}\right\}
$$

where $\theta_{A_{i}}^{1}$ is the vector of model $A_{i}$ specific parameters, for models $i=\{D H, R O T, U T I L, P R O D\}$ $\theta^{2}$ is the vector of parameters common across the models, and $\theta^{3}$ is the vector of parameters calibrating the shock processes. These three groups of parameters consist of the following

\footnotetext{
${ }^{17} I_{t}$ is calculated as the sum of durable consumption and private investment, $C_{t}$ is private consumption of nondurable goods and services. $W_{t}$ denote non-farm business sector compensation per hour and $H_{t}$ denote non-farm business sector hours of all persons. The real per capita variables are obtained dividing by labor force and the GDP deflator, $P_{Y, t}$. $G_{t}$ is given by government consumption expenditures and gross investment, and Taxes $_{t}$ are the tax revenues computed as the sum of personal current taxes, taxes on corporate income and contribution for government social insurance and $Y_{t}$ denotes GDP . The data for output and its components, and tx revenues are obtained from BEA, the data for the labor force and hours and wages are from the BLS and the Federal funds rate data is from St. Louis FRED.
} 
elements:

$$
\begin{gathered}
\theta_{D H}^{1}=\left\{\rho^{c}, b^{g}, \rho^{g g}\right\}, \quad \theta_{R O T}^{1}=\{\lambda\}, \quad \theta_{U T I L}^{1}=\{\nu, \phi\}, \quad \theta_{P R O D}^{1}=\left\{\alpha_{G}\right\}, \\
\theta^{2}=\left\{b^{c}, \alpha_{p}, \alpha_{w}, \kappa, \delta_{2} / \delta_{1}, \sigma, \alpha_{R}, \alpha_{\pi}, \alpha_{Y}, \alpha_{\tau}, \alpha_{\tau, y}\right\}, \\
\theta^{3}=\left\{\rho_{g}, \rho_{z}, \rho_{\Upsilon}, \rho_{d}, \rho_{p}, \rho_{w}, \sigma_{g}, \sigma_{z}, \sigma_{\Upsilon}, \sigma_{d}, \sigma_{r}, \sigma_{p}, \sigma_{w}, \sigma_{\tau}, \mu_{p}, \mu_{w}\right\} .
\end{gathered}
$$

Parameters presented in Table 1 are calibrated, either because it is conventional in the literature, or because estimating these parameters is problematic due to identification issues. The parameter governing the steady state share of capital is set at $\theta=0.3$. Following Altig, Christiano, Eichenbaum, and Linde (2011), the steady state growth rate of output, $\mu_{z^{*}}$, is calibrated at 1.0047, while the growth rate of the embodied technology is set at 1.0042 . The steady state gross rate of inflation is calibrated as $\pi=1.0086$, to match the average yearly rate of inflation of 3.5 percent. The intertemporal discount factor $\beta=0.999$. This relatively high value for $\beta$ ensures the steady state nominal interest rate is below 6 percent, because smaller values for $\beta$ implies unrealistically large steady state nominal interest rates. The steady state rate of capital utilization is $u=1$, while the steady state depreciation rate is fixed at a conventional value $\delta_{0}=0.025$. The actual average share of government expenditures in GDP, $G / Y=0.2$, is used to calibrate the steady state share of government expenditures in the model. Finally, we fix the elasticity of substitution for intermediate goods and labor types, because estimating these parameters is problematic. We set $\eta_{p}$ at 6 and $\eta_{w}$ at 21 , which imply the steady state price and wage markups of 20 and 5 percent correspondingly.

Column 2 of tables Tables 3 and 4 show the prior distribution of the estimated parameters in the five models. These distributions are chosen from beta, gamma or inverse gamma distributions. All parameters with bounded support have a beta prior, while gamma and inverse gamma distributions are chosen as priors for parameters bounded from below, such as parameters of the nominal rigidities, investment costs, and others. The priors for these parameters are centered at different values, dictated by the common knowledge generated by the empirical literature. The prior distribution for standard deviations of shock processes are completely flat (uniform) distributions over the subspace of positive values.

\subsection{Model Comparison}

To evaluate the relative quantitative performance of the models, we estimate and compare their marginal likelihoods. Suppose $Y_{T}=\left\{y_{t}\right\}_{t=1}^{T}$ is the observed history of vector $y_{t}$ up to 
period $T$, and $Y_{0}=\varnothing$. The posterior probability of model $A_{i}$ is determined by Bayes formula

$$
p\left(A_{i} \mid Y_{T}\right)=P\left(A_{i}\right) p\left(Y_{T} \mid A_{i}\right),
$$

where $P\left(A_{i}\right)$ is the prior probability, and $p\left(Y_{T} \mid A_{i}\right)$ is the marginal probability of $Y_{T}$, or the likelihood function. For any two models, $A_{i}$ and $A_{j}$ the posterior odds ratio is defined as

$$
\frac{p\left(A_{i} \mid Y_{T}\right)}{p\left(A_{j} \mid Y_{T}\right)}=\frac{P\left(A_{i}\right)}{P\left(A_{j}\right)}\left[\frac{p\left(Y_{T} \mid A_{i}\right)}{p\left(Y_{T} \mid A_{j}\right)}\right]
$$

where $\frac{P\left(A_{i}\right)}{P\left(A_{j}\right)}$ is the ratio of prior probabilities of the two models, called the prior odds ratio, and $\left[\frac{p\left(Y_{T} \mid A_{i}\right)}{p\left(y_{T} \mid A_{j}\right)}\right]$ is the ratio of marginal likelihoods of the two models, or the Bayes factor. Denoting $L(i \mid j)$ the loss incurred if choosing model $A_{i}$ when model $A_{j}$ is true, the expected posterior loss from choosing model $A_{i}$ is $P\left(A_{j} \mid Y_{T}\right) L(i \mid j)$. Then, one should choose model $A_{i}$ if the expected posterior loss from choosing it is smaller than that of the alternative model, or $P\left(A_{j} \mid Y_{T}\right) L(i \mid j)<P\left(A_{i} \mid Y_{T}\right) L(j \mid i)$. This expression can be rewritten as follows

$$
\frac{p\left(A_{i} \mid Y_{T}\right)}{p\left(A_{j} \mid Y_{T}\right)}>\frac{L(i \mid j)}{L(j \mid i)}
$$

the right hand side of which is usually called the Bayes critical value. Model $A_{i}$ should be preferred to model $A_{j}$ if the posterior odds ratio exceeds the Bayes critical value. Combining this expression and Equation (15), one can obtain that

$$
\frac{p\left(Y_{T} \mid A_{i}\right)}{p\left(Y_{T} \mid A_{j}\right)}>\frac{L(i \mid j)}{L(j \mid i)} \frac{P\left(A_{j}\right)}{P\left(A_{1}\right)} .
$$

If the researcher has prior beliefs about the validity of the two models, and is able to evaluate the relative cost of making a mistake regarding what the true model is, then the posterior odds ratio will provide enough information to choose the model that better explains the data $Y_{T}$. When there is no strong evidence regarding the prior odds or the Bayes critical value, it is reasonable to set $L(i \mid j)=L(j \mid i)$, and $P\left(A_{i}\right)=P\left(A_{j}\right)$. In this case, the model with the larger marginal likelihood should be chosen as the preferred model.

Since we do not want to create a bias in favor of any model, we assume all five models have equal prior probabilities, and the same expected posterior losses. We thus compare the models' marginal likelihoods, and leave it to the readers to adjust the reported results about the best fitted model using their prior beliefs.

To calculate the model's marginal likelihood, we implement the Harmonic mean estimator of Gelfand and Dey (1994), described in detail by Geweke (1999). Gelfand and Dey notice 
that for any p.d.f. $f(\theta)$ with the support in $\Theta$, the posterior mean of

$$
\frac{f(\theta)}{p\left(\theta \mid A_{i}\right) p\left(Y_{T} \mid \theta, A_{i}\right)}
$$

coincides with the inverse of the marginal likelihood of the model:

$$
E\left[\frac{f(\theta)}{p\left(\theta \mid A_{i}\right) p\left(Y_{T} \mid \theta, A_{i}\right)} \mid Y_{T}, A_{i}\right]=P^{-1}\left(Y_{T} \mid A_{i}\right)
$$

Suppose the support of $f(\theta)$ is $\hat{\Theta}_{M}=\left\{\theta:\left(\theta-\hat{\theta}_{M}\right)^{\prime} \hat{\Sigma}_{M}^{-1}\left(\theta-\hat{\theta}_{M}\right) \leq \chi_{1-p}^{2}(k)\right\}$, where $p$ is any number on interval $(0,1), \hat{\theta}_{M}=\frac{\sum_{m=1}^{M} \theta^{(m)}}{M}$ and $\hat{\Sigma}_{M}=\frac{\sum_{m=1}^{M}\left(\theta^{(m)}-\hat{\theta}_{M}\right)\left(\theta^{(m)}-\hat{\theta}_{M}\right)^{\prime}}{M}$, and $\chi_{1-p}^{2}(k)$ is the p-value of the $\chi^{2}$ distribution with $k$ degrees of freedom. Geweke (1999) shows that $f(\theta)$ defined on $\hat{\Theta}_{M}$ as

$$
f(\theta)=p^{-1}(2 \pi)^{-k / 2}\left|\hat{\Sigma}_{M}\right|^{-1 / 2} \exp \left[-(1 / 2)\left(\theta-\hat{\theta}_{M}\right)^{\prime} \hat{\Sigma}_{M}^{-1}\left(\theta-\hat{\theta}_{M}\right)\right],
$$

will guarantee the boundedness of expression (16), and thus the posterior mean will exist as long as the posterior density $p\left(\theta \mid Y_{T}, A_{i}\right)$ is uniformly bounded away from zero on every compact subset of $\Theta$.

To calculate the posterior expectation of the expression in (16), we evaluate the mean value of the elements of the Markov chain used to calculate the parameter estimate. As noted in Geweke (1999), the estimator may sometimes be very unstable. To confirm the stability of our results, we compute the marginal likelihood for different values of $p$.

\section{Estimation Results}

\subsection{Model Comparison}

The results of the model comparison exercise are presented in Table 2. The first column indicates the value of $p$ from Formula (17), used to calculate the marginal likelihood of the models. Column 2 provides the estimate of the log marginal likelihood for the baseline model, where we do not introduce any specific feature. Columns 3 - 6 show marginal likelihood less than that of the baseline model; therefore negative numbers indicate poorer fit of a model.

First of all, Table 2 reveals that the resulting model marginal likelihood values are very similar for all values of $p$. The log marginal likelihood of the baseline model (BL) is the largest, and varies around 5876 depending on the value of $p$. The models with productive government spending $(G$ in $F$ ) and government spending in utility ( $G$ in $U$ ) show very 
similar log marginal likelihood numbers, which are smaller than that of the baseline model by less than 1. The log likelihoods of models featuring deep habits (DH) and rule-of-thumb consumers (ROT) are approximately 14 and 8 smaller than that of the baseline model. Table 2 identifies the baseline model as the one with the best performance at describing the data. However, the explanatory power of other two models - the models with government spending in the utility function and production - makes them comparable to the best-fitting baseline model. While these two models demonstrate slightly more inferior fit, with the Bayes factor taking the largest value of $e^{0.9}$, the difference between these models is "barely worth mentioning", according to the classification in Jeffreys (1961). At contrast, the log marginal likelihood of the rule-of-thumb consumer model and deep habits model translates into a Bayes factors of $e^{8}$ and $e^{13}$ in favor of the baseline model, respectively, each of which is significantly greater than 1000. Therefore, Bayesian comparison is decisive in favor of the baseline model or models with productive and utility-deriving government spending.

The results of model comparison exercise suggest that introducing any of the considered transmission mechanisms for government spending is hardly beneficial for the model fit, because each of these mechanisms seems to reduce, rather than improve the model's explanatory power.

\subsection{Parameter Estimates}

Tables 3 and 4 report the estimated parameters in the five models. The estimates are obtained as mean values over 900,000 out of 1 million elements of the Markov chain generated using the random walk Metropolis-Hastings algorithm. The proposal distribution is multivariate normal with the variance-covariance matrix $c \Sigma$, where $\Sigma$ is determined as the inverse of the numerical Hessian evaluated at the starting element for the Markov chain, and $c>0$ is a parameter that is adjusted to achieve the acceptance rate in the range between 22 and 40 percent, as suggested in Robert and Casella (2005). ${ }^{18}$ The observation of the trace and cumulative sum (CUSUM) $\operatorname{plots}^{19}$ verify that Markov chains are stationary and convergent. Figures 6 - 10 show the plots of the estimated posterior distributions together with the priors (black curves). The plots demonstrate that the prior distributions are wide, and that posterior distributions are well defined and different from the priors.

Table 3 documents the estimates of model specific parameters and common parameters, besides the parameters of the shock processes. Although the models have different sets

\footnotetext{
${ }^{18}$ The starting element is determined as the mean value of the last 500 thousand draws of another (1 million elements long) Markov chain, the starting element of which coincides with the mean of the prior distribution.

${ }^{19}$ These are not reported in the paper but are available upon request from the authors.
} 
of model specific parameters, habit formation in private consumption is present in all the models. However, this parameter has a slightly different meaning across the models because of the unique specifications of the consumption measure $X_{t}$ entering utility. Consumption habit parameters for the deep habits model and the rule-of-thumb model are relatively similar and smaller than what is generally reported in the empirical literature (0.17 and 0.39 respectively). The baseline model, the model with productive government spending and model with government spending in utility report moderate habit formation parameters of approximately 0.7 , which is well within the range reported in the literature.

While the degree of deep habit for public consumption is considerably larger than for private consumption $\left(b^{g}=0.69\right)$, the stock of habit for public and private consumption depreciate at the similar pace $\left(\rho^{c}=0.21\right.$ and $\left.\rho^{g g}=0.26\right)$. Model specific parameter for the rule-of-thumb model, which determines the share of population living hand-to-mouth given by $\lambda$, is estimated to be 0.07 . This number is smaller than what is reported in the literature. For example, Cogan, Cwik, Taylor, and Wieland (2010) find $\lambda=0.29$, and using the European data, Forni, Monteforte, and Sessa (2009) estimate $\lambda=0.34$, while Coenen and Straub (2005) report $\lambda=0.246$. The estimates for the model with government spending in utility are $\nu$ and $\phi$. The elasticity of substitution between public and private consumption in the model where government spending enters utility, is $\nu=1.40$, which is larger than $\nu=0.3$ estimated in Bouakez and Rebei (2007), and implies less substitutability between government spending and private consumption than in their model. Parameter $\phi$ has the posterior mean of 0.94 indicating that private consumption is valued by individuals much more than public goods. The mean of the specific parameter in the model with productive government spending, $\alpha_{G}$, is estimated at 0.03. This value is close but smaller than the one calibrated in the study by Baxter and King (1993) (In their model, $\alpha_{G}=0.05$.)

The rest of Table 3 presents the estimates of the common model parameters. While there is some variation, the parameters are generally consistent across the models. The estimate of the price rigidity parameter varies greatly across the models, and $\alpha_{p}$ is in the range of 8 to 50 . With the exception of the deep habits model, all models demonstrate the wage rigidity parameter above 100. Investment adjustment costs parameter is also uniformly greater than 1 in all of the models, except the model featuring deep habits. It is worth noting that the parameter estimates for the deep habits model differs for many of the estimated parameters from the other models, and also the baseline model and the model where spending is productive and utility-enhancing have rather similar estimates across the three. For these three models the parameter $\sigma$ is estimated to be close to 0.5, which implies an intertemporal elasticity of substitution greater than 1 , while $\sigma$ is estimated to be slightly larger than 1 for the model with deep habits and rule-of-thumb consumers. Parameters of the monetary 
policy rule in all models imply that the rule is inertial, with $\alpha_{R}$ estimated in the range of 0.9. The response of the policy interest rate to inflation is moderate, with $\alpha_{\pi}$ varying between 0.07 and $0.15 .^{20}$ The estimates imply that the long term response of interest rates to inflation, $\alpha_{\pi} /\left(1-\alpha_{R}\right)$, is between 1.1 and 1.5 in all models. The response of the interest rate to output growth, measured by $\alpha_{Y}$ is small and fairly consistent across the models. Finally, the estimates of the tax rule are very similar across all the models - the tax rule is highly inertial ( $\alpha_{\tau}$ is approximately 0.95 ), with a small response to the output gap, where a one percent increase in output gap implies approximately 0.5 basis point increase in the income tax rate.

Table 4 reports the estimates of autocorrelation and standard deviations of the shock processes. The estimates for the government spending, investment specific, and monetary policy shocks are consistent across the models. Consistent with other studies, we find that the government spending process is highly persistent at 0.97. The autocorrelation of the investment specific shock lies within the range of $0.1-0.3$, and the standard deviation is approximately 0.03. The tax rule estimates are also consistent across all models, where the average tax rate is significantly persistent and has a positive response to output deviations in the range of 0.004 and 0.006 across all models. On the other hand, the models provide quite different estimates for the neutral technology and preference processes. It is important to understand however, that neither model can perfectly describe the properties of the data. When an estimated model is missing an internal mechanism to replicate some properties of the data, such as autocorrelations and volatilities, then the estimates of shock processes will be adjusted to replicate observed correlations in the data.

\subsection{Impulse Response Functions}

There has been a lot of debate in the literature about the effect of government spending on private consumption. The models we investigate in this paper were all developed with a channel to allow consumption to rise in response to an unexpected increase in government spending observed in many empirical structural VAR models. The literature however, has still not come to an agreement on this issue. While some authors report evidence favoring the positive response (see Ravn, Schmitt-Grohé, and Uribe (2007), Bouakez and Rebei (2007), Zubairy (2010)), others fail to find it in their estimated models (see for example Leeper, Plante, and Traum (2010), Coenen and Straub (2005)). We address this debate by comparing responses of consumption to the government spending shock across the estimated models.

\footnotetext{
${ }^{20}$ While the response to inflation is less than 1 , there is no indeterminacy of the equilibrium, because the long-run interest rate response to inflation, $\frac{\alpha_{\pi}}{1-\alpha_{R}}$ is still greater than 1 .
} 
Figure 3 plots the impulse response of consumption to a 1 percent increase in government spending in the five estimated models, shown as percentage deviations from trend, with quarters along the horizontal axis. Strikingly, none of the five models under consideration predicts a positive response of consumption to the shock. In fact, besides the model featuring rule-of-thumb consumers, even on impact the consumption response is negative and significantly different from zero among all of the models under consideration. Note that all five models have the potential to predict a positive consumption response to a government spending shock. To verify this, we conduct a prior predictive analysis of the consumption response, in the same spirit as it is done in Leeper, Traum, and Walker (2011). More precisely, we draw a random sample of 100 elements for the model parameter from their respective prior distributions, and then compute the impulse response functions. Figure 5, in the Appendix, shows the distribution of the consumption response to a positive 1 percent government spending shock across the five models. The figure reports the median as well as the 5th and 95th quantile of the distribution. Clearly, the range of the consumption response spans both positive and negative values on impact across all five models, which indicates that the estimated negative consumption responses are induced by the data, rather than by prior distributions.

Given the parameter estimates, it should not be surprising that the response of consumption is very similar across the baseline model, the model featuring productive government spending and the model where government spending affects utility. This is likely due to the small difference in the models caused by a near zero estimate for parameter $\left(\alpha_{G}\right)$ in the productive government model, and a small weight on public spending in the utility function, $(1-\phi)$. It is also possible to relate the negative consumption response to the fact that in these three estimated models, the posterior distribution of intertemporal elasticity of substitution for consumption, $\sigma$, turns out to be smaller than one. When $\sigma<1$, consumption and leisure are complements, meaning that $U_{12}>0$. This means that an equilibrium increase in labor (and drop in leisure) is associated with the decreasing marginal utility of consumption, providing incentives for the households to reduce consumption.

When $\sigma>1$, as is the case in the models with deep habits and rule-of-thumb consumers, consumption and leisure are substitutes in the sense that $U_{12}<0$. Therefore, the opposite is true: An increase in hours worked $h$ raises marginal utility of consumption, making it more desirable for households to raise consumption. Nevertheless, while $\sigma$ is estimated to be larger than 1 in the deep habits and rule-of-thumb consumer models, these models still predict a negative response of consumption. This might be due to the relatively low estimated share of liquidity constrained household in the rule-of-thumb model, at around 7 percent of the population, and in the case of the deep habits model, the low degree of deep habit formation 
at the level of the private consumption good. When $\sigma>1$, the larger the $\sigma$, the more negative is the labor elasticity of marginal utility, implying that an increase in hours raises the marginal utility of consumption to a larger extent with a larger $\sigma$. As a result, the larger adjustment in consumption should be observed. This can be seen from the log linear approximation to the consumption Euler equation. Ignoring habit formation for simplicity, it can be written as

$$
E_{t} \hat{c}_{t+1}-\hat{c}_{t} \sim \frac{h}{h-1} \frac{\zeta}{\sigma}\left(E_{t} \hat{h}_{t+1}-\hat{h}_{t}\right)+\frac{1}{\sigma}\left(\hat{R}_{t}-E_{t} \hat{\pi}_{t+1}\right)-E_{t} \hat{\mu}_{z^{*}, t+1}
$$

One can see from this equation, that the larger is $\sigma$, the smaller is responsiveness of consumption to changes in the real interest rate (consumption smoothing), and the larger is consumption responsiveness to changes in labor. Therefore, the larger estimate for $\sigma$ in the rule-of-thumb model could explain the least negative consumption response across the models.

Figure 4 shows output responses to a 1 percent increase in government spending across the five models. The responses are shown in percentage deviations from the non-stochastic trend, with quarters along the horizontal axis. The response of output is again similar for the baseline model, and the models featuring productive and utility-enhancing government spending. In these models, output rises close to 0.17 percent in response to a 1 percent government spending shock. Given that the steady state share of government spending was fixed at 0.2 , this translates into a government spending multiplier of less than one on impact, at approximately 0.85 in these three models. ${ }^{21}$ The response of output is slightly larger in the model featuring deep habits and rule-of-thumb consumers, however it implies that on impact, the government spending multiplier for output is greater than 1 in these models (approximately 1 in the deep habits model and 1.2 in the model featuring rule-of-thumb consumers.) Therefore, we conclude that the models disagree about the size of the impact government spending multiplier of output.

\subsection{Moments}

Because Bayesian estimation is the full information approach, it effectively is trying to match all moments and cross-correlations of the data and the model, rather than specific impulse responses as in the limited information estimation, such as the IRF matching estimator. To better understand the quality of the data fit by the models, we compare moments and autocorrelations predicted by the estimated models and the data. Tables 5 and 6 report

\footnotetext{
${ }^{21}$ The multiplier is computed as the impact response of output divided by the steady state ratio of public spending to output, which is 0.2 .
} 
unconditional moments and autocorrelations of model variables. The variables in the models are analogues of the observable variables in the data. In particular, the statistics for investment, consumption, and the wage rate are those of the growth rates of model variables, government spending statistics is government spending relative to the output level, while other variables (inflation, hours, interest rate, and the tax rate) are raw data generated by the models. The last column displays the statistics for the vector of observable variables used in estimation. All estimates in the tables are shown as the median values together with $5^{\text {th }}$ and $95^{\text {th }}$ quantiles of the posterior moment distributions; with quantiles reported in square brackets.

Table 5 focuses on standard deviations, both in absolute terms and relative to the standard deviation of output growth for the five models and in the data. While the models over-predict the volatilities of almost all variables, they do a reasonably good job matching the standard deviations relative to output growth. Similar to the data, all models report larger volatility of investment growth and smaller volatility of consumption growth relative to output growth. The only exception is the model with the rule of thumb consumers, for which consumption relative to output volatility is the largest and most different from the data. This inability to match the volatility of consumption growth may be a factor contributing to the relatively poor fit of the rule-of-thumb model. Note this increased volatility of consumption might be due to the presence of rule-of-thumb consumers who are not able to insure against the risk and are forced to consume their entire disposable income. Comparing model statistics with the data (in the last column), one may notice that all five models over-predict the relative volatilities of inflation and under-predict the relative volatility of taxes. The three best models with the closest fit to data, which include the baseline model and models featuring productive and utility-enhancing government spending exhibit similar moments. Among the other models, the model with deep habits under-predicts the relative volatility of investment growth relative to all the other models, whereas the baseline model comes closest to data. Also, the rule-of-thumb consumer model over-predicts the relative standard deviation of inflation, and consequently also interest rate.

Table 6 shows the serial correlations and correlations with output growth implied by the models and the data. All models do especially well at matching the persistence in inflation and the interest rate. While all models are able to match the correlation between output growth and consumption and investment growth reasonably well, matching the correlation of the rate of interest with output growth is problematic for all of them. ${ }^{22}$ Interestingly, the model featuring deep habits is notably able to match the negative correlation between

\footnotetext{
${ }^{22}$ This is also seen in other estimated DSGE models, see for example Justiniano, Primiceri, and Tambalotti (2011).
} 
inflation and output growth. This can be explained by the fact that in the deep habits model, firms take into account future expected demand relative to current demand when setting prices, and thus the Phillips curve has both current and expected future demand in the expression. ${ }^{23}$ However, the poor fit of the deep habits model can be partially explained by the very low auto-correlation for consumption in the model and the large correlation between wage and output growth, which is contrary to data. Wage dynamics in the deep habits model reflect the countercyclicality of markups, and the resulting pro-cyclicality of marginal costs, like wages.

Table 7 reports the contribution of the government spending shock to the overall volatility of macroeconomic variables implied by each model. Each column in the table shows model implied standard deviation of a variable when government spending is the only source of uncertainty, relative to the unconditional standard deviation of this variable assuming all sources of uncertainly are present, in percentages. Consistent with other studies, in all models the government spending shock explains only a moderate fraction of volatility for most variables. Specifically, the contribution of the government spending shock to consumption is not exceeding 10 percent, which points to the limited importance of government spending shocks in generating consumption fluctuations.

\section{Conclusion}

In this paper, we rely on Bayesian estimation to quantitatively investigate five distinct models of the government spending shock. We find that the model with the best fit to the data is the basic New Keynesian model with nominal frictions, where government spending represents a mere waste of economy's resources, and utility is nonseparable in consumption and leisure. The remaining four models feature propagation mechanisms for the government spending shock that were originally introduced in an attempt to explain a positive correlation between private and public consumption conditional on a spending shock, a finding often documented in empirical research. Namely, the models in this study incorporate deep habits in consumption, rule-of-thumb consumers, government spending directly influencing utility of economic agents, and the idea of productive public capital. However, we do not find support for this co-movement hypothesis in either of the models we consider. In particular, all the estimated models predict a drop in consumption as a response to an unexpected rise in government spending.

\footnotetext{
${ }^{23}$ Refer to Zubairy (2013) for a more detailed discussion of the Phillips curve under deep habits.
} 


\section{References}

Altig, D., L. Christiano, M. Eichenbaum, and J. Linde (2011): "Firm-Specific Capital, Nominal Rigidities and the Business Cycle," Review of Economic Dynamics, $14(2), 225-247$.

Ambler, S., and A. Paquet (1996): "Fiscal Spending Shocks, Endogenous Government Spending, and Real Business Cycles," Journal of Economic Dynamics and Control, 20(13), 237-256.

Baxter, M., And R. G. King (1993): "Fiscal Policy in General Equilibrium," American Economic Review, 83(3), 315-34.

Bilbite, F. O. (2009): "Nonseparable Preferences, Fiscal Policy Puzzles, and Inferior Goods," Journal of Money, Credit and Banking, 41(2-3), 443-450.

Bils, M. (1987): "The Cyclical Behavior of Marginal Cost and Price," American Economic Review, 77(5), 838-55.

Blanchard, O., and R. Perotti (2002): "An Empirical Characterization Of The Dynamic Effects Of Changes In Government Spending And Taxes On Output," The Quarterly Journal of Economics, 117(4), 1329-1368.

Bouakez, H., and N. Rebei (2007): "Why does Private Consumption Rise After a Government Spending Shock?," Canadian Journal of Economics, 40(3), 954-979.

Coenen, G., and R. Straub (2005): "Does Government Spending Crowd in Private Consumption? Theory and Empirical Evidence for the Euro Area," International Finance, 8(3), 435-470.

Cogan, J. F., T. Cwik, J. B. Taylor, and V. Wieland (2010): "New Keynesian versus Old Keynesian Government Spending Multipliers," Journal of Economic Dynamics and Control, 34(3), 281-295.

Colciago, A. (2011): "Rule-of-Thumb Consumers Meet Sticky Wages," Journal of Money, Credit and Banking, 43, 325-353.

Fatas, A., And I. Mihov (2001): "The Effects of Fiscal Policy on Consumption and Employment: Theory and Evidence," CEPR Discussion Papers 2760, C.E.P.R. Discussion Papers.

Fisher, J. (2003): "Technology Shocks Matter," FRB of Chicago w.p \#2002-14, December.

Fisher, J., And R. Peters (2010): "Using Stock Returns to Identify Government Spending Shocks," Economic Journal, 120(544), 414-436.

Forni, L., L. Monteforte, and L. Sessa (2009): "The General Equilibrium Effects of Fiscal Policy: Estimates for the Euro Area," Journal of Public Economics, 93(3-4), $559-585$. 
Furlanetto, F. (2011): "Fiscal Stimulus and the Role of Wage Rigidity," Journal of Economic Dynamics and Control, 35(4), 512-527.

Galí, J., J. D. Lopez-Salido, and J. VAllés (2007): "Understanding the Effects of Government Spending on Consumption," Journal of the European Economic Association, $5(1), 227-270$.

Ganelli, G., and J. Tervala (2009): "Can Government Spending Increase Private Consumption? The Role of Complementarity," Economics Letters, 103(1), 5-7.

Gelfand, A. E., And D. K. Dey (1994): "Bayesian Model Choice: Asymptotics and Exact Calculations," Journal of the Royal Statistical Society. Series B (Methodological), 56(3), 501-514.

Geweke, J. (1999): "Using Simulation Methods for Bayesian Econometric Models: Inference, Development, and Communication," Econometric Reviews, 18(1), 1-73.

JACOB, P. (2013): "Deep Habits, Price Rigidities and the Consumption response to Government spending," Reserve Bank of New Zealand Discussion Paper Series DP2013/03.

Jeffreys, H. (1961): The Theory of Probability. Oxford University Press.

Justiniano, A., G. Primiceri, and A. Tambalotti (2011): "Investment Shocks and the Relative Price of Investment," Review of Economic Dynamics, 14(1), 101-121.

King, R. G., C. I. Plosser, and S. T. Rebelo (1988): "Production, Growth and Business Cycles : The Basic Neoclassical Model," Journal of Monetary Economics, 21(23), 195-232.

Kormilitsina, A. (2013): "Solving Rational Expectations Models with Informational Subperiods: A Perturbation Approach," Computational Economics, 41(4), 525-555.

Leeper, E. M., M. Plante, and N. Traum (2010): "Dynamics of Fiscal Financing in the United States," Journal of Econometrics, 156(2), 304-321.

Leeper, E. M., N. Traum, and T. B. Walker (2011): "Clearing Up the Fiscal Multiplier Morass," NBER Working Paper 17444.

Linnemann, L. (2006): "The Effect of Government Spending on Private Consumption: A Puzzle?," Journal of Money, Credit and Banking, 38(7), 1715-1735.

Linnemann, L., And A. Schabert (2003): "Fiscal Policy in the New Neoclassical Synthesis," Journal of Money, Credit and Banking, 35(6), 911-29.

(2004): "Can Fiscal Spending Stimulate Private Consumption?," Economics Letters, 82(2), 173-179.

(2006): "Productive Government Expenditure In Monetary Business Cycle Models," Scottish Journal of Political Economy, 53(1), 28-46. 
Monacelli, T., and R. Perotti (2008): "Fiscal Policy, Wealth Effects, and Markups," NBER Working Papers 14584, National Bureau of Economic Research, Inc.

Mountford, A., And H. Uhlig (2009): "What are the Effects of Fiscal Policy Shocks?," Journal of Applied Econometrics, 24(6), 960-992.

Perotti, R. (2008): "In Search of the Transmission Mechanism of Fiscal Policy," in NBER Macroeconomics Annual 2007, Volume 22, NBER Chapters, pp. 169-226. National Bureau of Economic Research, Inc.

Ramey, V. A. (2011): "Identifying Government Spending Shocks: It's all in the Timing," The Quarterly Journal of Economics, 126(1), 1-50.

Ravn, M., S. Schmitt-Grohé, and M. Uribe (2006): "Deep Habits," Review of Economic Studies, 73(1), 195-218.

Ravn, M. O., S. Schmitt-Grohé, and M. Uribe (2007): "Explaining the Effects of Government Spending Shocks on Consumption and the Real Exchange Rate," NBER Working Papers 13328, National Bureau of Economic Research, Inc.

Robert, C. P., and G. Casella (2005): Monte Carlo Statistical Methods (Springer Texts in Statistics). Springer-Verlag New York, Inc., Secaucus, NJ, USA.

Rotemberg, J. J. (1982): "Sticky Prices in the United States," Journal of Political Economy, 90(6), 1187-1211.

Rotemberg, J. J., and M. Woodford (1991): "Markups and the Business Cycle," in NBER Macroeconomics Annual 1991, Volume 6, NBER Chapters, pp. 63-140. National Bureau of Economic Research, Inc.

(1999): "The Cyclical Behavior of Prices and Costs," in Handbook of Macroeconomics, ed. by J. B. Taylor, and M. Woodford, vol. 1 of Handbook of Macroeconomics, chap. 16, pp. 1051-1135. Elsevier.

Smets, F., And R. Wouters (2007): "Shocks and Frictions in US Business Cycles: A Bayesian DSGE Approach," American Economic Review, 97(3), 586-606.

Traum, N., and S.-C. Yang (2010): "When Does Government Debt Crowd Out Investment?," Caepr Working Papers 2010-006, Center for Applied Economics and Policy Research, Economics Department, Indiana University Bloomington.

Zubairy, S. (2010): "On Fiscal Multipliers: Estimates from a Medium Scale DSGE Model," Working Papers 10-30, Bank of Canada.

\footnotetext{
Macroeconomic Dynamics, forthcoming.
} 


\section{$6 \quad$ Tables and Figures}

Table 1: Parameter calibration and steady state values

\begin{tabular}{c|c|c}
\hline \hline \multicolumn{3}{c}{ Common parameters } \\
\hline$\theta$ & Production: capital share & 0.3 \\
$\mu_{z^{*}}$ & Growth of output & 1.0047 \\
$\mu_{\Upsilon}$ & Growth of investment specific technology & 1.0042 \\
$\pi$ & Steady state inflation & 1.0086 \\
$\beta$ & Intertemporal discount factor & 0.999 \\
$\delta_{0}$ & Depreciation rate & 0.025 \\
$\varrho$ & Shadow price of capital & 1 \\
$u$ & Steady state rate of capital utilization & 1 \\
$h$ & Steady state labor & 0.5 \\
$s^{g}$ & Steady state share of govt. spending in output & 0.2 \\
$\eta_{p}$ & Prices: elasticity of substitution & 6 \\
$\eta_{w}$ & Wages: elasticity of substitution & 21 \\
$\tau$ & Steady state tax rate & 0.18 \\
\hline \multicolumn{3}{c}{ Model with productive public capital } \\
\hline$s^{g c}$ & Consumption share of public spending & 0.8 \\
\hline \hline
\end{tabular}

Table 2: Model marginal likelihood

\begin{tabular}{c|c|c|c|c|c}
\hline \hline $\mathrm{p}$ & BL & DH vs. BL & ROT vs. BL & G in U vs. BL & G in F vs. BL \\
\hline 0.1 & 5874.3 & -13.9 & -8.1 & -0.4 & -0.5 \\
0.5 & 5876.4 & -13.9 & -8.2 & -0.4 & -0.6 \\
0.9 & 5878.8 & -14.4 & -8.1 & -0.6 & -0.9 \\
\hline \hline
\end{tabular}

Notes. Table shows logarithm of marginal likelihood of a model evaluated using Geweke (1999) procedure. The first column is the parameter $p$ in the Geweke estimator that specifies the supplementary p.d.f $f(\theta)$ in Equation (17). The second column shows the marginal likelihood in the baseline model. Columns 3-6 present the log of marginal likelihood of a model relative to the best fitted model, so that negative numbers indicate more poor fit. $\mathrm{DH}=$ model with deep habits, $\mathrm{ROT}=$ for rule-of-thumb model, $\mathrm{G}$ in $\mathrm{U}=$ model with government spending in the utility function, $\mathrm{G}$ in $\mathrm{F}$ = the model with government spending in the production technology, and $\mathrm{BL}=$ the baseline model with no specific features. 
Table 3: Parameter Estimates: Part I

\begin{tabular}{|c|c|c|c|c|c|c|c|}
\hline \multirow[t]{2}{*}{ Parameter } & \multicolumn{2}{|c|}{ Prior distribution } & \multirow{2}{*}{$\begin{array}{c}\text { DH } \\
\text { Mean } \\
\text { (st.d.) }\end{array}$} & \multirow{2}{*}{$\begin{array}{l}\text { ROT } \\
\text { Mean } \\
\text { (st.d.) }\end{array}$} & \multirow{2}{*}{$\begin{array}{l}\text { G in U } \\
\text { Mean } \\
\text { (st.d.) }\end{array}$} & \multirow{2}{*}{$\begin{array}{c}\mathrm{G} \text { in } \mathrm{F} \\
\text { Mean } \\
\text { (st.d) }\end{array}$} & \multirow{2}{*}{$\begin{array}{c}\text { Baseline } \\
\begin{array}{c}\text { Mean } \\
\text { (st.d.) }\end{array}\end{array}$} \\
\hline & Type & $\begin{array}{l}\text { Mean } \\
\text { (st.d.) }\end{array}$ & & & & & \\
\hline$b^{c}$ & B & 0.5 & 0.172 & 0.386 & 0.697 & 0.699 & 0.695 \\
\hline & & (0.2) & $(0.028)$ & $(0.043)$ & $(0.028)$ & $(0.031)$ & $(0.031)$ \\
\hline$\rho^{c}$ & B & 0.5 & 0.205 & - & - & $\begin{array}{lll}- & \\
\end{array}$ & - \\
\hline & & $(0.2)$ & $(0.082)$ & (-) & $(-)$ & (-) & (-) \\
\hline$b^{g}$ & B & 0.5 & 0.690 & - & - & - & - \\
\hline & & $(0.2)$ & $(0.098)$ & $(-)$ & $(-)$ & $(-)$ & (-) \\
\hline$\rho^{g g}$ & B & 0.5 & 0.261 & - & - & - & - \\
\hline & & (0.2) & $(0.129)$ & (-) & $(-)$ & $(-)$ & (-) \\
\hline$\lambda$ & B & 0.2 & - & 0.073 & - & - & - \\
\hline & & (0.1) & $(-)$ & $(0.018)$ & $(-)$ & $(-)$ & (-) \\
\hline$\alpha_{G}$ & I & 0.1 & - & - & - & 0.026 & - \\
\hline & & $(0.1)$ & $(-)$ & (-) & $(-)$ & $(0.016)$ & $(-)$ \\
\hline$\nu$ & G & 0.8 & - & - & 1.402 & - & - \\
\hline & & $(0.5)$ & $(-)$ & (-) & $(0.464)$ & $(-)$ & (-) \\
\hline$\phi$ & B & 0.8 & - & - & 0.942 & - & - \\
\hline & & $(0.1)$ & $(-)$ & (-) & $(0.021)$ & $(-)$ & $(-)$ \\
\hline$\alpha_{p}$ & G & 20.0 & 8.914 & 13.637 & 42.548 & 46.925 & 46.839 \\
\hline & & $\begin{array}{l}(5.0) \\
1000\end{array}$ & $\begin{array}{l}(1.203) \\
51.428\end{array}$ & $(1.532)$ & $\begin{array}{l}(4.847) \\
100.917\end{array}$ & $(5.089)$ & $\begin{array}{c}(5.001) \\
107.151\end{array}$ \\
\hline$\alpha_{w}$ & $G$ & $\begin{array}{c}100.0 \\
(30.0)\end{array}$ & $\begin{array}{c}51.428 \\
(6.499)\end{array}$ & $\begin{array}{c}110.502 \\
(21.675)\end{array}$ & $\begin{array}{l}109.218 \\
(13.270)\end{array}$ & $\begin{array}{l}110.108 \\
(17.574)\end{array}$ & $(16.215)$ \\
\hline$\alpha_{R}$ & B & 0.7 & 0.887 & 0.939 & 0.905 & 0.906 & 0.906 \\
\hline & & $(0.2)$ & $(0.008)$ & $(0.005)$ & $(0.007)$ & $(0.007)$ & $(0.007)$ \\
\hline$\alpha_{\pi}$ & G & 0.5 & 0.144 & 0.072 & 0.106 & 0.106 & 0.105 \\
\hline & & $(0.2)$ & $(0.008)$ & $(0.005)$ & $(0.007)$ & $(0.007)$ & $(0.007)$ \\
\hline$\alpha_{Y}$ & G & 0.1 & 0.026 & 0.040 & 0.023 & 0.022 & 0.022 \\
\hline & & $(0.1)$ & $(0.003)$ & $(0.004)$ & $(0.003)$ & $(0.003)$ & $(0.003)$ \\
\hline$\kappa$ & G & 1.0 & 0.186 & 1.025 & 1.115 & 1.187 & 1.196 \\
\hline & & $(0.5)$ & $(0.032)$ & $(0.122)$ & $(0.121)$ & $(0.127)$ & $(0.129)$ \\
\hline$\delta_{2} / \delta_{1}$ & G & 2.0 & 1.557 & 2.697 & 4.833 & 4.125 & 4.138 \\
\hline & & $(0.5)$ & $(0.288)$ & $(0.340)$ & $(0.572)$ & $(0.437)$ & $(0.445)$ \\
\hline$\sigma$ & G & 2.0 & 1.041 & 1.225 & 0.495 & 0.519 & 0.516 \\
\hline & & (0.5) & $(0.069)$ & $(0.107)$ & $(0.038)$ & $(0.040)$ & $(0.039)$ \\
\hline$\alpha_{\tau}$ & B & 0.8 & 0.941 & 0.969 & 0.949 & 0.949 & 0.950 \\
\hline & & $(0.1)$ & $(0.011)$ & $(0.012)$ & $(0.013)$ & $(0.013)$ & $(0.013)$ \\
\hline$\alpha_{\tau, y}$ & I & 0.01 & 0.005 & 0.004 & 0.006 & 0.006 & 0.005 \\
\hline & & $(0.1)$ & $(0.002)$ & $(0.002)$ & $(0.004)$ & $(0.004)$ & $(0.003)$ \\
\hline
\end{tabular}

Notes. Table shows prior distributions and Bayesian estimates of parameters across different models. Notation in the second columns is as follows: $B=$ beta, $G=$ gamma, $I=$ inverse gamma distributions. Estimates are presented as mean values and standard deviations across the last 900,000 out of 1 million elements of a Markov chain generated using the Metropolis Hastings algorithm. Kalman filter is used to evaluate the likelihood of the data. 
Table 4: Parameter Estimates: Part II

\begin{tabular}{c|c|c|ccccc}
\hline \hline Parameter & Prior distribution & DH & ROT & G in U & G in F & Baseline \\
\hline \multirow{5}{*}{$\rho_{g}$} & Type & $\begin{array}{c}\text { Mean } \\
\text { (st.d.) }\end{array}$ & $\begin{array}{c}\text { Mean } \\
(\text { st.d.) }\end{array}$ & $\begin{array}{c}\text { Mean } \\
\text { (st.d.) }\end{array}$ & $\begin{array}{c}\text { Mean } \\
\text { (st.d.) }\end{array}$ & $\begin{array}{c}\text { Mean } \\
\text { (st.d) }\end{array}$ & Mean \\
(st.d.) \\
\hline
\end{tabular}

Notes. Table shows prior distributions and Bayesian estimates of parameters across different models. Notation in the second columns is as follows: $B=$ beta, $G=$ gamma, $I=$ inverse gamma distributions. Estimates are presented as mean values and standard deviations across the last 900,000 out of 1 million elements of a Markov chain generated using the Metropolis Hastings algorithm. Kalman filter is used to evaluate the likelihood of the data. 
Table 5: Unconditional second moments in the models and data

\begin{tabular}{|c|c|c|c|c|c|c|}
\hline & Deep Habits & ROT & G in Utility & Productive $\mathrm{G}$ & Baseline & Data \\
\hline \multirow{3}{*}{ Investment } & \multicolumn{6}{|c|}{ Standard Deviations } \\
\hline & 5.86 & 5.34 & 7.14 & 7.18 & 7.17 & 3.56 \\
\hline & {$[5.09,6.52]$} & {$[4.51,6.15]$} & {$[5.97,8.20]$} & {$[6.01,8.26]$} & {$[6.02,8.73]$} & \\
\hline \multirow[t]{2}{*}{ Consumption } & 2.02 & 1.72 & 1.55 & 1.54 & 1.55 & 0.57 \\
\hline & {$[1.80,2.35]$} & {$[1.52,1.91]$} & {$[1.33,1.84]$} & {$[1.38,1.80]$} & {$[1.37,1.82]$} & \\
\hline \multirow[t]{2}{*}{ Inflation } & 2.69 & 3.94 & 2.85 & 2.90 & 2.80 & 0.59 \\
\hline & {$[2.27,3.42]$} & {$[3.28,4.59]$} & {$[2.37,3.41]$} & {$[2.42,3.42]$} & {$[2.36,3.47]$} & \\
\hline \multirow[t]{2}{*}{ Wage rate } & 1.46 & 1.62 & 1.32 & 1.39 & 1.37 & 0.59 \\
\hline & {$[1.25,1.63]$} & {$[1.43,1.89]$} & {$[1.16,1.56]$} & {$[1.21,1.60]$} & {$[1.18,1.57]$} & \\
\hline \multirow[t]{2}{*}{ Hours } & 9.58 & 8.86 & 12.64 & 14.11 & 13.13 & 5.77 \\
\hline & {$[6.37,16.84]$} & {$[6.94,12.58]$} & {$[9.15,19.06]$} & {$[9.72,21.19]$} & {$[9.69,20.31]$} & \\
\hline \multirow{2}{*}{ Government Spending } & 11.46 & 10.09 & 13.74 & 14.57 & 13.83 & 7.44 \\
\hline & {$[6.84,20.20]$} & {$[7.17,13.99]$} & {$[7.69,22.16]$} & {$[9.68,25.15]$} & {$[9.37,21.56]$} & \\
\hline \multirow[t]{2}{*}{ Interest rate } & 2.14 & 2.76 & 1.96 & 1.86 & 1.73 & 0.85 \\
\hline & {$[1.38,3.46]$} & {$[1.80,4.51]$} & {$[1.31,2.50]$} & {$[1.26,2.80]$} & {$[1.27,2.85]$} & \\
\hline \multirow[t]{2}{*}{ Tax rate } & 6.91 & 8.58 & 7.24 & 6.97 & 7.00 & 10.12 \\
\hline & {$[5.32,9.10]$} & {$[6.12,14.01]$} & {$[5.24,10.49]$} & {$[5.55,11.31]$} & {$[4.91,9.90]$} & \\
\hline \multirow{3}{*}{ Investment } & & andard $D$ & viation Relc & ive to Output & rowth & \\
\hline & 2.09 & 2.74 & 3.72 & 3.43 & 3.19 & 3.69 \\
\hline & {$[1.88,2.38]$} & {$[2.43,3.19]$} & {$[3.31,4.31]$} & {$[3.05,4.13]$} & {$[2.73,3.70]$} & \\
\hline \multirow[t]{2}{*}{ Consumption } & 0.78 & 0.87 & 0.70 & 0.66 & 0.71 & 0.59 \\
\hline & {$[0.70,0.88]$} & {$[0.77,1.01]$} & {$[0.62,0.81]$} & {$[0.59,0.79]$} & {$[0.61,0.82]$} & \\
\hline \multirow[t]{2}{*}{ Inflation } & 0.88 & 1.74 & 1.68 & 1.51 & 1.32 & 0.61 \\
\hline & {$[0.79,1.00]$} & {$[1.54,2.02]$} & {$[1.50,1.95]$} & {$[1.35,1.82]$} & {$[1.13,1.53]$} & \\
\hline \multirow[t]{2}{*}{ Wage rate } & 0.54 & 0.80 & 0.70 & 0.64 & 0.58 & 0.61 \\
\hline & {$[0.49,0.62]$} & {$[0.71,0.93]$} & {$[0.62,0.81]$} & {$[0.57,0.78]$} & {$[0.49,0.67]$} & \\
\hline \multirow[t]{2}{*}{ Hours } & 3.59 & 4.96 & 6.26 & 5.76 & 6.04 & 5.96 \\
\hline & {$[3.22,4.08]$} & {$[4.39,5.78]$} & {$[5.57,7.26]$} & {$[5.12,6.94]$} & {$[5.15,6.99]$} & \\
\hline \multirow[t]{2}{*}{ Government Spending } & 2.97 & 5.31 & 7.81 & 9.58 & 6.86 & 7.70 \\
\hline & {$[2.67,3.38]$} & {$[4.69,6.17]$} & {$[6.94,9.05]$} & {$[8.51,11.54]$} & {$[5.86,7.94]$} & \\
\hline \multirow[t]{2}{*}{ Interest rate } & 0.53 & 1.18 & 1.27 & 0.84 & 1.00 & 0.88 \\
\hline & {$[0.47,0.60]$} & {$[1.05,1.38]$} & {$[1.13,1.48]$} & {$[0.75,1.01]$} & {$[0.85,1.16]$} & \\
\hline \multirow[t]{2}{*}{ Tax rate } & 2.36 & 4.01 & 3.72 & 4.18 & 3.15 & 10.47 \\
\hline & {$[2.12,2.68]$} & {$[3.55,4.67]$} & {$[3.31,4.31]$} & {$[3.71,5.03]$} & {$[2.69,3.65]$} & \\
\hline
\end{tabular}

Notes: The table shows the standard deviations of the observable variables. The moments reported are the median values of the moment distribution created by generating an artificial sample with the same length as our dataset (225 observations) after discarding the 50 initial observations, for a random sample of 100 parameter draws from the Markov chain obtained as part of the model estimation procedure. The numbers in the brackets give the 5 th and 95 th percentile numbers for the moments. 
Table 6: Unconditional correlations in the models and data

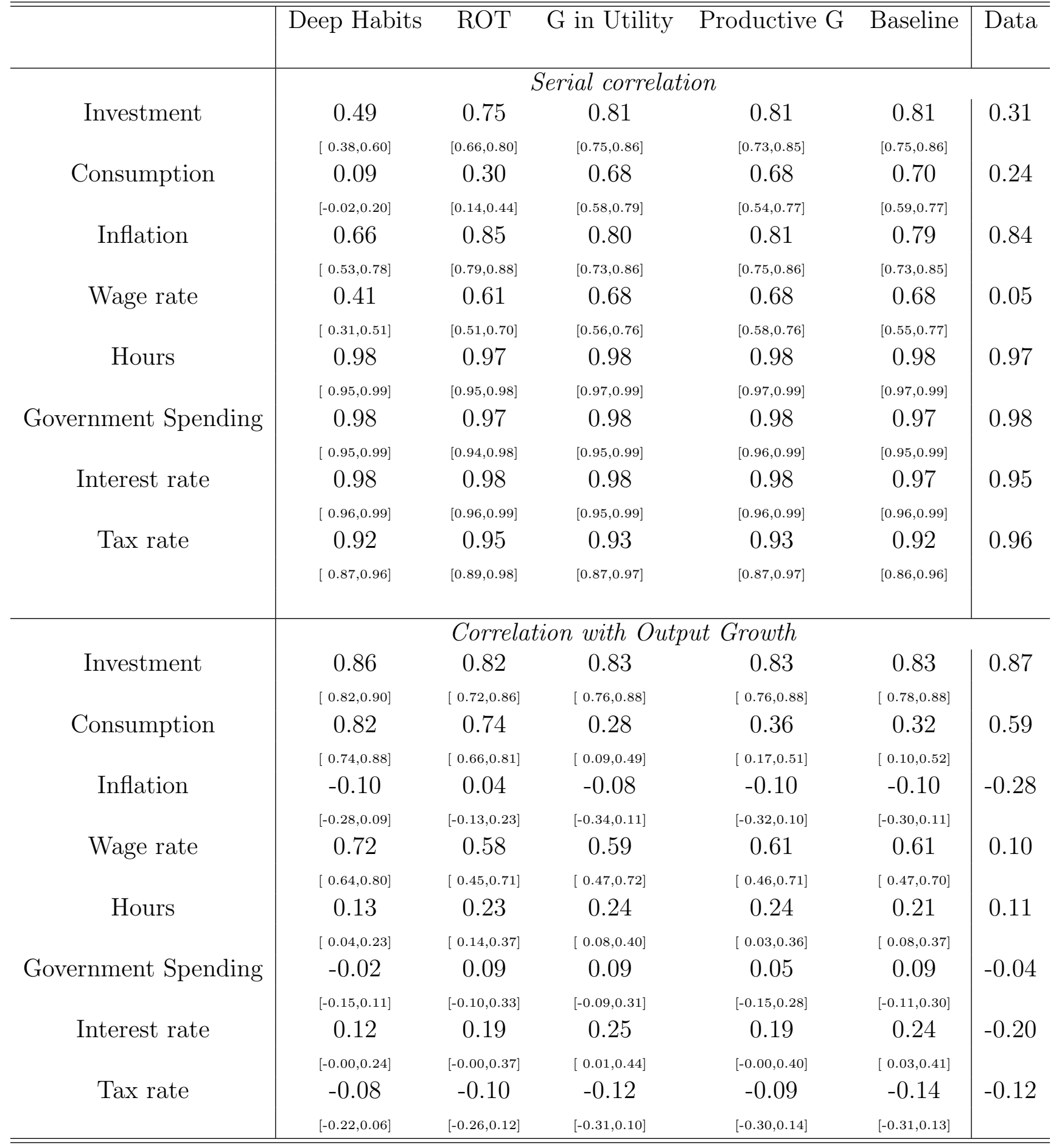

Notes: The table shows the correlations of the observable variables. The moments reported are the median values of the moment distribution created by generating an artificial sample with the same length as our dataset (225 observations) after discarding the 50 initial observations, for a random sample of 100 parameter draws from the Markov chain obtained as part of the model estimation procedure. The numbers in the brackets give the 5th and 95th percentile numbers for the moments. 
Table 7: Contribution of the government spending shock to model volatility, \%

\begin{tabular}{c|ccccc}
\hline \hline & Deep Habits & ROT & G in Utility & Productive G & Baseline \\
\hline Investment & 4.38 & 2.70 & 1.06 & 0.99 & 1.04 \\
& {$[2.49,6.84]$} & {$[1.45,3.93]$} & {$[0.69,1.51]$} & {$[0.57,1.33]$} & {$[0.67,1.44]$} \\
Consumption & 5.96 & 3.22 & 8.82 & 7.31 & 7.52 \\
& {$[4.23,7.76]$} & {$[2.60,7.43]$} & {$[7.49,10.31]$} & {$[6.54,8.35]$} & {$[6.79,8.64]$} \\
Inflation & 8.63 & 9.61 & 4.79 & 3.81 & 3.81 \\
& {$[7.10,10.37]$} & {$[7.17,11.93]$} & {$[3.64,6.84]$} & {$[2.78,4.78]$} & {$[2.79,4.77]$} \\
Wage rate & 3.70 & 3.66 & 1.38 & 1.52 & 1.65 \\
& {$[1.41,6.15]$} & {$[0.86,5.58]$} & {$[0.94,1.88]$} & {$[1.10,1.98]$} & {$[1.22,2.15]$} \\
Hours & 4.52 & 10.15 & 3.08 & 3.46 & 3.51 \\
Interest rate & {$[3.00,7.48]$} & {$[8.09,20.17]$} & {$[1.94,5.39]$} & {$[1.99,5.05]$} & {$[2.33,5.24]$} \\
& 1.17 & 4.28 & 1.06 & 2.07 & 1.12 \\
Tax rate & {$[0.91,1.44]$} & {$[2.99,5.82]$} & {$[0.66,1.29]$} & {$[1.44,2.68]$} & {$[0.79,1.38]$} \\
& 0.43 & 0.60 & 0.75 & 0.83 & 0.75 \\
& {$[0.15,1.14]$} & {$[0.23,2.33]$} & {$[0.25,1.81]$} & {$[0.32,1.81]$} & {$[0.25,2.13]$} \\
\hline \hline
\end{tabular}

Notes: The table shows the standard deviations in a model with government spending shock as a ratio of unconditional model implied standard deviation, in percentages. The reported numbers are the median values created by a random subsample of 100 elements of a Markov chain obtained as part of the model estimation procedure. The numbers in the brackets give the 5th and 95th percentile shares. 


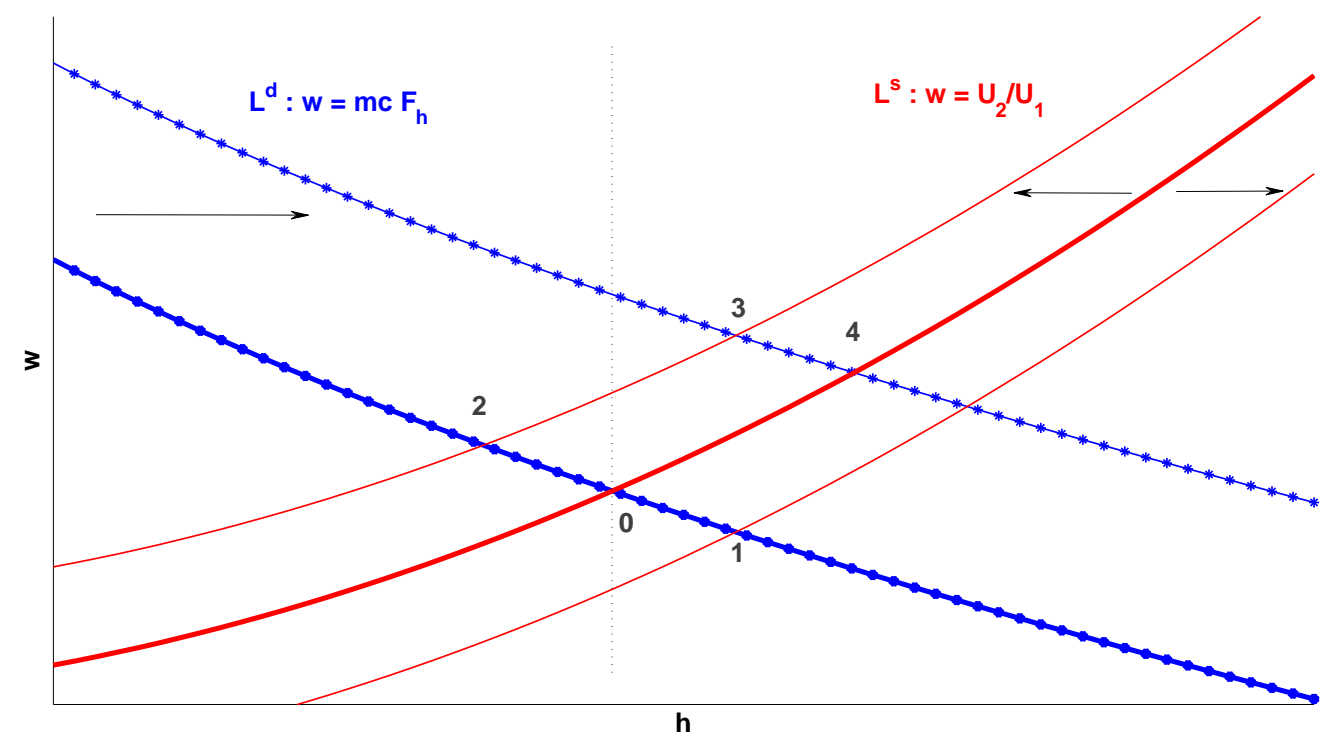

Figure 1: Effect of the government spending shock in labor market.

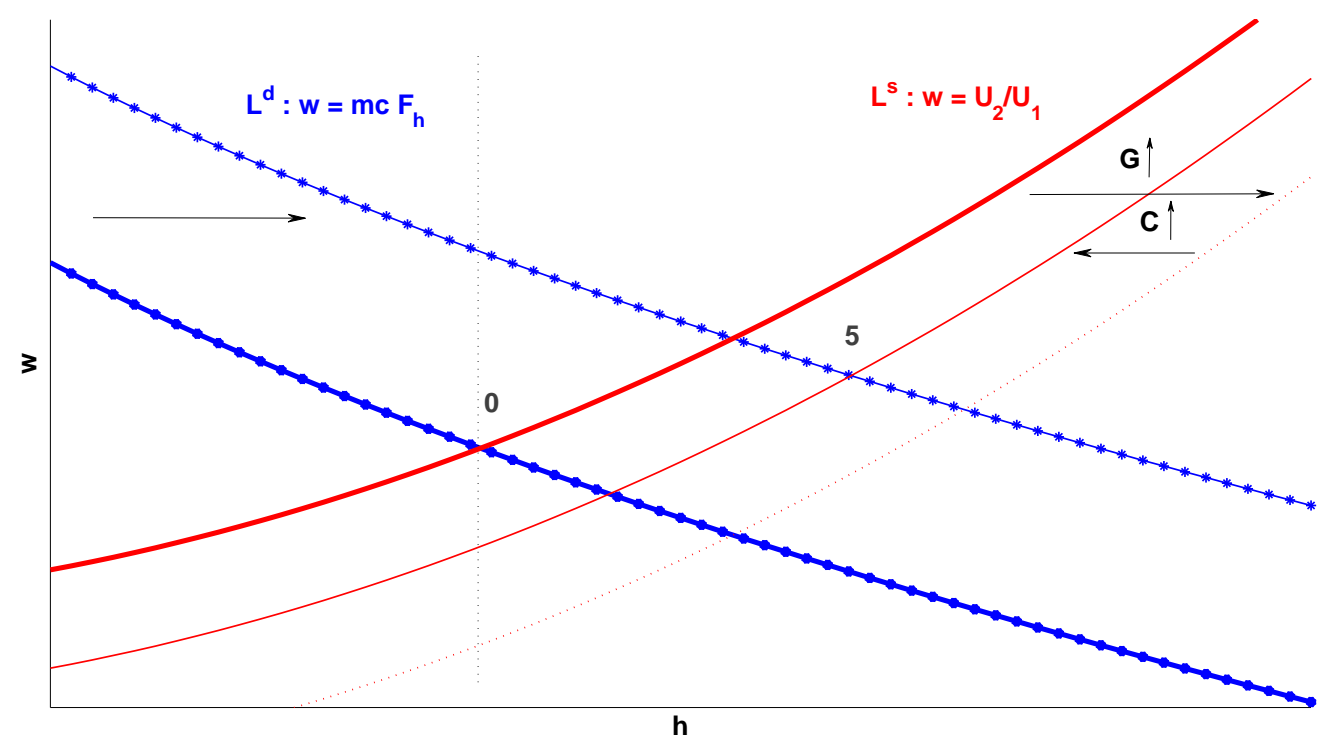

Figure 2: Effect of the government spending shock in labor market in the model where government spending affects utility. 

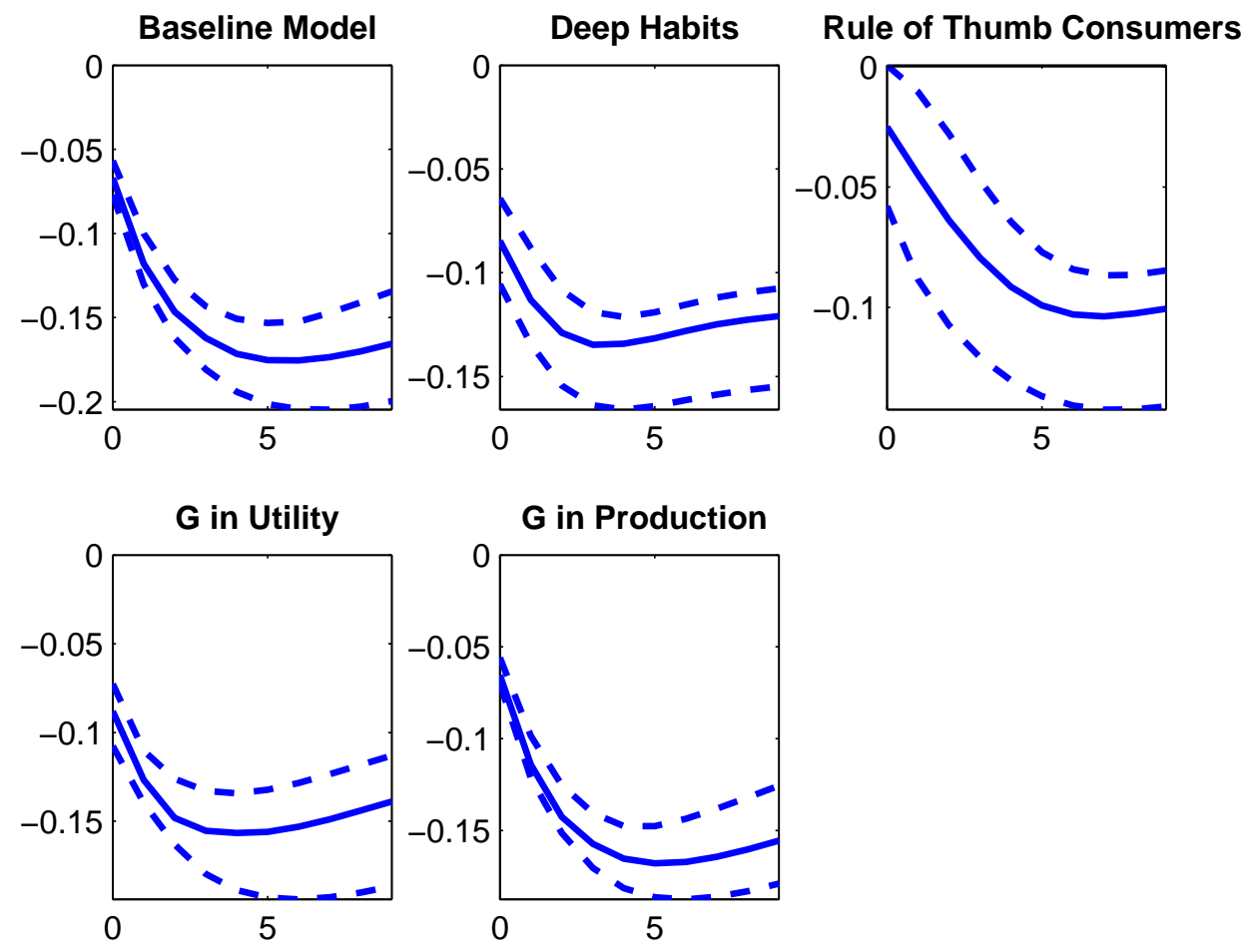

Figure 3: Consumption response to the government spending shock

Notes: Each graph shows an impulse response to the government spending shock in percentage deviations from trend. Quarters are along the horizontal axis, and percentages are on the vertical axis. Each response is calculated as the median value of the impulse response distribution created by a random subsample of 100 elements of a Markov chain obtained as part of the model estimation procedure. The dashed lines show the $5^{\text {th }}$ and $95^{t h}$ quantile of this distribution. 

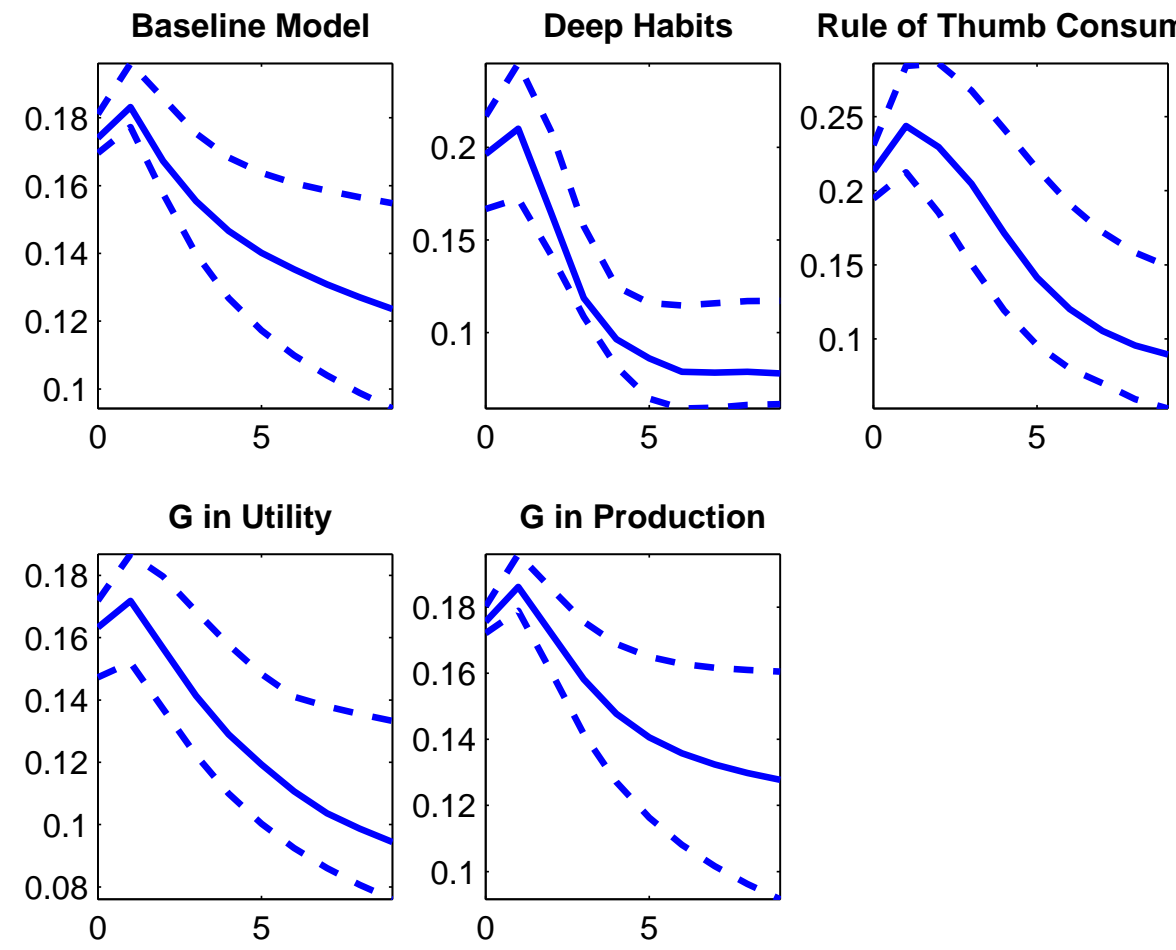

Figure 4: Output response to the government spending shock

Notes: Each graph shows an impulse response to the government spending shock in percentage deviations from trend. Quarters are along the horizontal axis, and percentages are on the vertical axis. Each response is calculated as the median value of the impulse response distribution created by a random subsample of 100 elements of a Markov chain obtained as part of the model estimation procedure. The dashed lines show the $5^{\text {th }}$ and $95^{\text {th }}$ quantile of this distribution. 

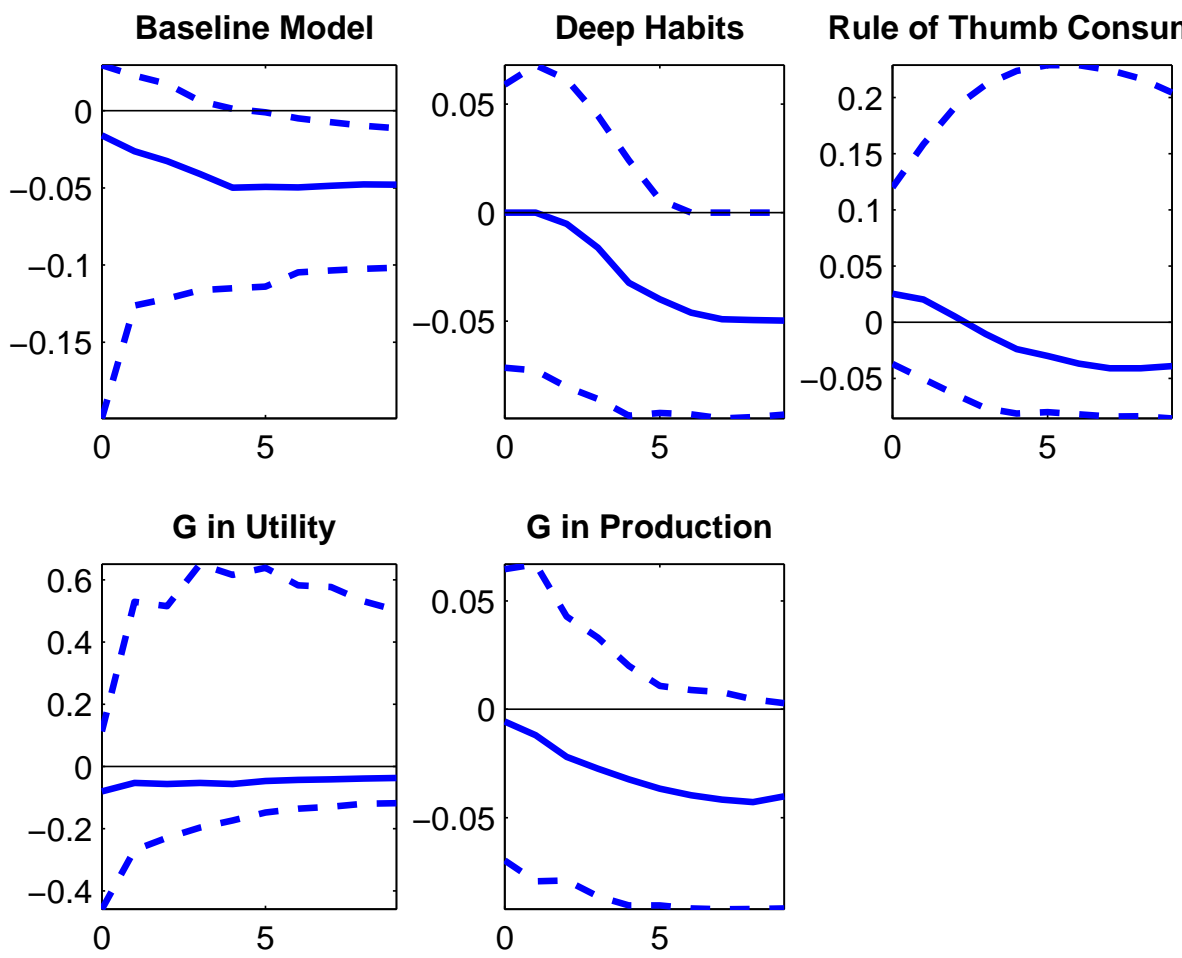

Figure 5: Prior predictive analysis: Consumption response to the government spending shock under priors

Notes: Each graph shows an impulse response to the government spending shock in percentage deviations from trend. Quarters are along the horizontal axis, and percentages are on the vertical axis. Each response is calculated as the median value of the impulse response distribution created by a random sample of 100 elements for the model parameter from their respective prior distributions. The dashed lines show the $5^{\text {th }}$ and $95^{\text {th }}$ quantile of this distribution. 


\section{Not for Publication Appendix}

\subsection{Symmetric Equilibrium in Stationary Variables}

Stationary transformations of model variables are presented in Table 7.1.

\begin{tabular}{c|c|c}
\hline \hline Original variable & Stationarized variable & How stationary variable was obtained \\
\hline$\Psi(\cdot), \Omega(\cdot)$ & $\psi(\cdot), \omega(\cdot)$ & divided by $Z^{*}$ \\
$R_{t}^{k}$ & $r_{t}^{k}$ & multiplied by $\Upsilon_{t}$ \\
$K_{t+1}, I_{t}$ & $k_{t+1}, i_{t}$ & divided by $Z_{t}^{*} \Upsilon_{t}$ \\
$Y_{t}, C_{t}, X_{t}, W_{t}, G_{t}$ & $y_{t}, c_{t}, x_{t}, w_{t}, g_{t}$ & divided by $Z_{t}^{*}$ \\
\hline \hline
\end{tabular}

Stationary version of the intratemporal utility $U\left(X_{t}, h_{t}\right)$ is obtained through transformation $u\left(x_{t}, h_{t}\right)=\frac{U\left(X_{t}, h_{t}\right)}{\left(Z_{t}^{*}\right)^{1-\sigma}}$; therefore $u\left(x_{t}, h_{t}\right)$ is defined as

$$
u\left(x_{t}, h_{t}\right) \equiv \frac{x_{t}^{1-\sigma}}{1-\sigma}\left(1-h_{t}\right)^{\zeta}
$$

For the steady state to exist, the following two relationships must hold between the growth rates of shocks and model variables:

$$
\mu_{z^{*}, t}=\mu_{\Upsilon, t}^{\theta /(1-\theta)} \mu_{z, t}, \quad \mu_{I, t}=\mu_{\Upsilon, t} \mu_{z^{*}, t}
$$

Denote $\tilde{\beta}_{t}=\beta\left(\mu_{z, t}^{*}\right)^{1-\sigma}$. Then, The F.O.C. w.r.t. state contingent assets pins down $r_{t, t+1}$ :

$$
r_{t, t+1}=\tilde{\beta}_{t+1} \frac{\xi_{t+1}}{\xi_{t} \pi_{t+1} \mu_{z^{*}, t+1}}
$$

where $\xi_{t}$ is the lagrange multiplier near the household's budget constraint in stationary terms. Optimization by firms provides the following two F.O.C.s

$$
\begin{gathered}
r_{t}^{k}=m c_{t} q_{t} \theta\left(\frac{u_{t} k_{t}}{h_{t} \mu_{I, t}}\right)^{\theta-1}, \\
w_{t}=m c_{t} q_{t}(1-\theta)\left(\frac{u_{t} k_{t}}{h_{t} \mu_{I, t}}\right)^{\theta},
\end{gathered}
$$

where $m c_{t}$ is the stationary marginal costs of firms. Given the assumed functional form for $\delta\left(u_{t}\right)$ in Equation (5), the optimal choice of capital services supplied by households implies

$$
\left(1-\tau_{t}\right) r_{t}^{k}=\varrho_{t}\left(\delta_{1}+\delta_{2}\left(u_{t}-u\right)\right)
$$

where $\varrho_{t}$ is the multiplier shadow price of future capital. The costs of investment, price and wage adjustments can be written in stationary variables as:

$$
\mathcal{S}\left(\frac{i_{t+1}}{i_{t}} \mu_{I, t+1}\right)=\frac{\kappa}{2}\left(\frac{i_{t+1}}{i_{t}} \mu_{I, t+1}-\mu_{I}\right)^{2},
$$




$$
\begin{gathered}
\omega\left(\pi_{t}\right)=\frac{\alpha_{p}}{2}\left(\pi_{t}-\pi\right)^{2} \\
\psi\left(\frac{w_{t}}{w_{t-1}} \mu_{z^{*}, t} \pi_{t}\right)=\frac{\alpha_{w}}{2}\left(\frac{w_{t}}{w_{t-1}} \mu_{z^{*}, t} \pi_{t}-\mu_{z^{*}} \pi\right)^{2} .
\end{gathered}
$$

The dynamics of capital in stationary variables is

$$
k_{t+1}=\left(1-\delta\left(u_{t}\right)\right) \frac{k_{t}}{\mu_{I, t}}+i_{t}\left(1-\mathcal{S}\left(\frac{i_{t+1}}{i_{t}} \mu_{I, t+1}\right)\right) .
$$

The optimal choice for future capital is driven by the F.O.C.

$$
\varrho_{t}=E_{t}\left[\tilde{\beta}_{t+1} \frac{\xi_{t+1}}{\xi_{t} \mu_{I, t+1}}\left(\left(1-\tau_{t+1}\right) u_{t+1} r_{t+1}^{k}+\varrho_{t+1}\left(1-\delta\left(u_{t+1}\right)\right)\right)\right]
$$

and the optimal choice of investment is given by:

$$
\begin{gathered}
1=\varrho_{t}\left(1-\frac{\kappa}{2}\left(\frac{i_{t+1}}{i_{t}} \mu_{I, t+1}-\mu_{I}\right)^{2}-\kappa\left(\frac{i_{t}}{i_{t-1}} \mu_{I, t}-\mu_{I}\right) \frac{i_{t}}{i_{t-1}} \mu_{I, t}\right)+ \\
\left.E_{t} \tilde{\beta}_{t+1} \frac{\xi_{t+1}}{\xi_{t} \mu_{I, t+1}} \varrho_{t+1} \kappa\left(\frac{i_{t+1}}{i_{t}} \mu_{I, t+1}-\mu_{I}\right)\left(\frac{i_{t+1}}{i_{t}}\right)^{2} \mu_{I, t+1}\right],
\end{gathered}
$$

The optimality condition for the choice of the wage rate is

$$
\begin{gathered}
\psi^{\prime}\left(\frac{w_{t}}{w_{t-1}} \mu_{z^{*}, t} \pi_{t}\right) \frac{w_{t}}{w_{t-1}} \pi_{t} \mu_{z^{*}, t} h_{t}=\left(1-\eta_{w}\right)\left(1-\tau_{t}-\psi\left(\frac{w_{t}}{w_{t-1}} \mu_{z^{*}, t} \pi_{t}\right)\right) h_{t}+\frac{\eta_{w}}{\mu_{t}} h_{t}+ \\
E_{t} \tilde{\beta}_{t+1} \frac{\xi_{t+1}}{\xi_{t}} \psi^{\prime}\left(\frac{w_{t+1}}{w_{t}} \mu_{z^{*}, t+1} \pi_{t+1}\right)\left(\frac{w_{t+1}}{w_{t}}\right)^{2} \mu_{z^{*}, t+1} \pi_{t+1} h_{t+1},
\end{gathered}
$$

where $\mu_{t}$ is the lagrange multiplier for the constraint on labor demand in the optimal choice of the wage rate by households. The optimal choice of state-contingent securities by optimizing households implies

$$
\xi_{t}=R_{t} E_{t} \tilde{\beta}_{t+1} \frac{\xi_{t+1}}{\mu_{z^{*}, t+1} \pi_{t+1}} .
$$

The monetary policy rule in terms of stationary variables is

$$
\log \left(\frac{R_{t}}{R}\right)=\alpha_{R} \log \left(\frac{R_{t-1}}{R}\right)+\alpha_{\pi} \log \left(\frac{\pi_{t}}{\pi}\right)+\alpha_{Y} \log \left(\frac{y_{t}}{y_{t-1}} \frac{\mu_{z^{*}, t}}{\mu_{z^{*}}}\right)+\log \left(\epsilon_{t}^{r}\right),
$$

and the tax rule is given by

$$
\log \left(\tau_{t} / \tau\right)=\alpha_{\text {tau }} \log \left(\tau_{t} / \tau\right)+\alpha_{\tau, y} \log \left(y_{t-1} / y\right)+\epsilon_{t}^{\tau} .
$$

The aggregate market clearing condition in the market for goods is

$$
y_{t}=c_{t}+g_{t}+i_{t}+\psi\left(\frac{w_{t}}{w_{t-1}} \mu_{z^{*}, t} \pi_{t}\right) w_{t} h_{t}
$$


where

$$
y_{t}=q_{t}\left(\frac{u_{t} k_{t}}{\mu_{I, t}}\right)^{\theta} h_{t}^{1-\theta}-\vartheta-\omega\left(\pi_{t}\right) .
$$

\subsubsection{Model with Deep Habits: Equilibrium}

Effective stationarized consumption entering utility in Equation (18) in the deep habits model is

$$
x_{t}=c_{t}-b^{c} \frac{s_{t-1}^{c}}{\mu_{z^{*}, t}}
$$

where the stock of habit $s_{t}^{c}$ is

$$
s_{t}^{c}=\rho^{c} \frac{s_{t-1}^{c}}{\mu_{z^{*}, t}}+\left(1-\rho^{c}\right) c_{t} .
$$

Household optimality condition for the choice of consumption is

$$
\xi_{t}=d_{t} u_{1}\left(x_{t}, h_{t}\right)
$$

Household optimality condition for the labor decision is

$$
w_{t}\left(1-\tau_{t}-\psi\left(\frac{w_{t}}{w_{t-1}} \mu_{z^{*}, t} \pi_{t}\right)\right) \xi_{t}=-d_{t} u_{2}\left(x_{t}, h_{t}\right) \mu_{t} .
$$

The optimal choice of prices by firms results in the following Phillips curve

$\pi_{t} \omega^{\prime}\left(\pi_{t}\right)=\left(1-\eta_{p}+\eta_{p} m c_{t}\right)\left(y_{t}-\omega\left(\pi_{t}\right)\right)-\eta_{p}\left(\tilde{\nu}_{t}^{c} x_{t}+\tilde{\nu}_{t}^{g} x_{t}^{g}-\left(1-m c_{t}\right)\left(c_{t}+g_{t}\right)\right)+E_{t} \tilde{\beta}_{t+1} \frac{\xi_{t+1}}{\xi_{t}} \pi_{t+1} \omega^{\prime}\left(\pi_{t+1}\right)$,

where

$$
\begin{gathered}
x_{t}^{g}=g_{t}-b^{g} \frac{s_{t-1}^{g}}{\mu_{z^{*}, t}} \\
s_{t}^{g}=\rho^{g g} \frac{s_{t-1}^{g}}{\mu_{z^{*}, t}}+\left(1-\rho^{g g}\right) g_{t}, \\
\left(\tilde{\nu}_{t}^{c}+m c_{t}-1\right)=E_{t} \tilde{\beta}_{t+1} \frac{\xi_{t+1}}{\xi_{t} \mu_{z^{*}, t+1}}\left[\rho^{c}\left(\tilde{\nu}_{t+1}^{c}+m c_{t+1}-1\right)+\left(1-\rho^{c}\right) b^{c} \tilde{\nu}_{t+1}^{c}\right], \\
\left(\tilde{\nu}_{t}^{g}+m c_{t}-1\right)=E_{t} \tilde{\beta}_{t+1} \frac{\xi_{t+1}}{\xi_{t} \mu_{z^{*}, t+1}}\left[\rho^{g}\left(\tilde{\nu}_{t+1}^{g}+m c_{t+1}-1\right)+\left(1-\rho^{g}\right) b^{g} \tilde{\nu}_{t+1}^{g}\right],
\end{gathered}
$$

A symmetric competitive equilibrium is the sequence of 27 variables, $\left\{y_{t}, r_{t}^{k}, m c_{t}, u_{t}, \varrho_{t}, i_{t}, k_{t+1}, w_{t}, \xi_{t}, R_{t}, c_{t}, h_{t}, \mu_{t}, \pi_{t}, x_{t}, x_{t}^{g}, s_{t}^{c}, s_{t}^{g}, \tilde{\nu}_{t}^{c}, \tilde{\nu}_{t}^{g}, g_{t}, \mu_{z, t}, \mu_{\Upsilon, t}, d_{t}, \eta_{t}^{p}, \eta_{t}^{w}, \tau_{t}\right\}_{t=0}^{\infty}$ that satisfies the system of 27 equations: (1), (3), (6), (8), (9), (10), (19) - (30), and (31) (39), for each sequence of innovations $\left\{\epsilon_{t}^{g}, \epsilon_{t}^{z}, \epsilon_{t}^{\Upsilon}, \epsilon_{t}^{d}, \epsilon_{t}^{p}, \epsilon_{t}^{w}, \epsilon_{t}^{R}, \epsilon_{t}^{\tau}\right\}_{t=0}^{\infty}$. 


\subsubsection{Model with Rule-of-Thumb Consumers: Equilibrium}

The aggregate consumption $c_{t}$ is

$$
c_{t}=(1-\lambda) c_{t}^{o}+\lambda c_{t}^{r}
$$

where

$$
c_{t}^{r}=w_{t} h_{t}\left(1-\tau_{t}-\psi\left(\frac{w_{t}}{w_{t-1}} \mu_{z^{*}, t} \pi_{t}\right)\right)+t r^{r},
$$

where $t r^{r}$ is a lump-sum transfer, and $c_{t}^{o}$ is consumption of optimizing households. Effective stationarized consumption of optimizing households entering utility in Equation (18) is

$$
x_{t}^{o}=c_{t}^{o}-b^{c} \frac{c_{t-1}^{o}}{\mu_{z^{*}, t}} .
$$

The optimality condition for the choice of consumption by optimizing households is

$$
\xi_{t}=d_{t} u_{1}\left(x_{t}^{o}, h_{t}\right)-E_{t} \frac{\tilde{\beta}_{t+1} b^{c}}{\mu_{z^{*}, t+1}} d_{t+1} u_{1}\left(x_{t+1}^{o}, h_{t+1}\right) .
$$

The optimality condition for the choice of labor by optimizing households is

$$
w_{t}\left(1-\tau_{t}-\psi\left(\frac{w_{t}}{w_{t-1}} \mu_{z^{*}, t} \pi_{t}\right)\right) \xi_{t}=-d_{t} u_{2}\left(x_{t}^{o}, 1-h_{t}\right) \mu_{t} .
$$

The Phillips curve is

$$
\pi_{t} \omega^{\prime}\left(\pi_{t}\right)=\left(1-\eta_{p}+\eta_{p} m c_{t}\right)\left(y_{t}-\omega\left(\pi_{t}\right)\right)+E_{t} \tilde{\beta}_{t+1} \frac{\xi_{t+1}}{\xi_{t}} \pi_{t+1} \omega^{\prime}\left(\pi_{t+1}\right) .
$$

A symmetric competitive equilibrium is the sequence of 22 variables,

$$
\left\{y_{t}, r_{t}^{k}, m c_{t}, u_{t}, \varrho_{t}, i_{t}, k_{t+1}, w_{t}, \xi_{t}, R_{t}, c_{t}, h_{t}, \mu_{t}, \pi_{t}, c_{t}^{o}, d_{t}, g_{t}, \mu_{z, t}, \mu_{\Upsilon, t}, \tau_{t}, \eta_{t}^{w}, \eta_{t}^{p}\right\}_{t=0}^{\infty}
$$

that satisfies the system of 22 equations: (1), (3), (6), (8), (9), (10), (19) - (30), and (40) (43), for each sequence of innovations $\left\{\epsilon_{t}^{g}, \epsilon_{t}^{z}, \epsilon_{t}^{\Upsilon}, \epsilon_{t}^{d}, \epsilon_{t}^{p}, \epsilon_{t}^{w}, \epsilon_{t}^{R}, \epsilon_{t}^{\tau}\right\}_{t=0}^{\infty}$.

\subsubsection{Model with Government Spending in the Utility Function: Equilibrium}

Effective stationarized consumption in Equation (18) is

$$
x_{t}=\tilde{c}_{t}-b^{c} \frac{\tilde{c}_{t-1}}{\mu_{z^{*}, t}},
$$

where

$$
\tilde{c}_{t}=\left(\phi c_{t}^{(\nu-1) / \nu}+(1-\phi) g_{t}^{(\nu-1) / \nu}\right)^{\nu /(\nu-1)} .
$$


The household's optimality condition for consumption choice is

$$
\xi_{t}=d_{t} u_{1}\left(x_{t}, h_{t}\right)-E_{t} \tilde{\beta}_{t+1} d_{t+1} u_{1}\left(x_{t+1}, h_{t+1}\right) \frac{b^{c}}{\mu_{z^{*}, t+1}} .
$$

The household's optimality condition for the labor decision is

$$
w_{t}\left(1-\tau_{t}-\psi\left(\frac{w_{t}}{w_{t-1}} \mu_{z^{*}, t} \pi_{t}\right)\right) \xi_{t}=-d_{t} u_{2}\left(x_{t}, h_{t}\right) \mu_{t}
$$

The Phillips curve is

$$
\pi_{t} \omega^{\prime}\left(\pi_{t}\right)=\left(1-\eta_{p}+\eta_{p} m c_{t}\right)\left(y_{t}-\omega\left(\pi_{t}\right)\right)+E_{t} \tilde{\beta}_{t+1} \frac{\xi_{t+1}}{\xi_{t}} \pi_{t+1} \omega^{\prime}\left(\pi_{t+1}\right) .
$$

A symmetric competitive equilibrium is the sequence of 21 variables,

$$
\left\{y_{t}, r_{t}^{k}, m c_{t}, u_{t}, \varrho_{t}, i_{t}, k_{t+1}, w_{t}, \xi_{t}, R_{t}, c_{t}, h_{t}, \mu_{t}, \pi_{t}, d_{t}, g_{t}, \mu_{z, t}, \mu_{\Upsilon, t}, \tau_{t}, \eta_{t}^{w}, \eta_{t}^{p}\right\}_{t=0}^{\infty}
$$

that satisfies the system of 21 equations, (1), (3), (6), (8), (9), (10), (19) - (30), and (44) (46), for each sequence of innovations $\left\{\epsilon_{t}^{g}, \epsilon_{t}^{z}, \epsilon_{t}^{\Upsilon}, \epsilon_{t}^{d}, \epsilon_{t}^{p}, \epsilon_{t}^{w}, \epsilon_{t}^{R}, \epsilon_{t}^{\tau}\right\}_{t=0}^{\infty}$.

\subsubsection{Model with Productive Government Spending: Equilibrium}

The evolution of public capital:

$$
k_{t+1}^{g}=\left(1-\delta\left(u_{t}\right)\right) k_{t}^{g}+i_{t}^{g},
$$

where stationary public capital and investment are, respectively, $k_{t+1}^{g}=K_{t+1}^{g} /\left(Z_{t}^{*} \Upsilon_{t}\right)$, and $i_{t}^{g}=I_{t}^{G} /\left(Z_{t}^{*} \Upsilon_{t}\right)$. Because public investment is a constant share of government expenditures,

$$
i_{t}^{g}=\left(1-s^{g c}\right) g_{t}
$$

Effective stationarized consumption in Equation(18) is

$$
x_{t}=c_{t}-b^{c} \frac{c_{t-1}}{\mu_{z^{*}, t}} \text {. }
$$

The household's optimality condition for the consumption decision is

$$
\xi_{t}=d_{t} u_{1}\left(x_{t}, h_{t}\right)-E_{t} \tilde{\beta}_{t+1} d_{t+1} u_{1}\left(x_{t+1}, h_{t+1}\right) \frac{b^{c}}{\mu_{z^{*}, t+1}} .
$$

Household's optimality condition for the labor decision is

$$
w_{t}\left(1-\tau_{t}-\psi\left(\frac{w_{t}}{w_{t-1}} \mu_{z^{*}, t} \pi_{t}\right)\right) \xi_{t}=-d_{t} u_{2}\left(x_{t}, h_{t}\right) \mu_{t}
$$


The Phillips curve is

$$
\pi_{t} \omega^{\prime}\left(\pi_{t}\right)=\left(1-\eta_{p}+\eta_{p} m c_{t}\right)\left(y_{t}-\omega\left(\pi_{t}\right)\right)+E_{t} \tilde{\beta}_{t+1} \frac{\xi_{t+1}}{\xi_{t}} \pi_{t+1} \omega^{\prime}\left(\pi_{t+1}\right) .
$$

A symmetric competitive equilibrium is the sequence of 22 variables,

$$
\left\{y_{t}, r_{t}^{k}, m c_{t}, u_{t}, \varrho_{t}, i_{t}, k_{t+1}, k_{t+1}^{g}, w_{t}, \xi_{t}, R_{t}, c_{t}, h_{t}, \mu_{t}, \pi_{t}, d_{t}, g_{t}, \mu_{z, t}, \mu_{\Upsilon, t}, \tau_{t}, \eta_{t}^{w}, \eta_{t}^{p}\right\}_{t=0}^{\infty}
$$

that satisfies the system of 22 equations: (1), (3), (6), (8), (9), (10), (19) - (30), and (47) (50), for each sequence of innovations $\left\{\epsilon_{t}^{g}, \epsilon_{t}^{z}, \epsilon_{t}^{\Upsilon}, \epsilon_{t}^{d}, \epsilon_{t}^{p}, \epsilon_{t}^{w}, \epsilon_{t}^{R}, \epsilon_{t}^{\tau}\right\}_{t=0}^{\infty}$.

\subsubsection{Baseline Model: Equilibrium}

Effective stationarized consumption in Equation(18) is

$$
x_{t}=c_{t}-b^{c} \frac{c_{t-1}}{\mu_{z^{*}, t}} .
$$

The household's optimality condition for the consumption decision is

$$
\xi_{t}=d_{t} u_{1}\left(x_{t}, h_{t}\right)-E_{t} \tilde{\beta}_{t+1} d_{t+1} u_{1}\left(x_{t+1}, h_{t+1}\right) \frac{b^{c}}{\mu_{z^{*}, t+1}} .
$$

Household's optimality condition for the labor decision is

$$
w_{t}\left(1-\tau_{t}-\psi\left(\frac{w_{t}}{w_{t-1}} \mu_{z^{*}, t} \pi_{t}\right)\right) \xi_{t}=-d_{t} u_{2}\left(x_{t}, h_{t}\right) \mu_{t}
$$

The Phillips curve is

$$
\pi_{t} \omega^{\prime}\left(\pi_{t}\right)=\left(1-\eta_{p}+\eta_{p} m c_{t}\right)\left(y_{t}-\omega\left(\pi_{t}\right)\right)+E_{t} \tilde{\beta}_{t+1} \frac{\xi_{t+1}}{\xi_{t}} \pi_{t+1} \omega^{\prime}\left(\pi_{t+1}\right) .
$$

A symmetric competitive equilibrium is the sequence of 21 variables,

$$
\left\{y_{t}, r_{t}^{k}, m c_{t}, u_{t}, \varrho_{t}, i_{t}, k_{t+1}, w_{t}, \xi_{t}, R_{t}, c_{t}, h_{t}, \mu_{t}, \pi_{t}, d_{t}, g_{t}, \mu_{z, t}, \mu_{\Upsilon, t}, \tau_{t}, \eta_{t}^{w}, \eta_{t}^{p}\right\}_{t=0}^{\infty}
$$

that satisfies the system of 21 equations: (1), (3), (6), (8), (9), (10), (19) - (30), and (51) (53), for each sequence of innovations $\left\{\epsilon_{t}^{g}, \epsilon_{t}^{z}, \epsilon_{t}^{\Upsilon}, \epsilon_{t}^{d}, \epsilon_{t}^{p}, \epsilon_{t}^{w}, \epsilon_{t}^{R}, \epsilon_{t}^{\tau}\right\}_{t=0}^{\infty}$.

\subsection{Steady State}

In all models, $\tilde{\beta}=\beta\left(\mu_{z^{*}}\right)^{1-\sigma}, \mu_{z}=\mu_{z^{*}} / \mu_{\Upsilon}^{\frac{\theta}{1-\theta}}, \mu_{I}=\mu_{\Upsilon} \mu_{z^{*}}, R=\pi \mu_{z^{*}} / \tilde{\beta}, r^{k}=\left(\mu_{I} / \tilde{\beta}-1+\right.$ $\left.\delta_{0}\right) /(1-\tau), \mu=\eta_{w} /\left(\eta_{w}-1\right) /(1-\tau), \delta_{1}=(1-\tau) r^{k} / \varrho$. In all models except the model with deep habits, $m c=1-1 / \eta_{p}$. In the deep habits model,

$$
m c=1-\frac{1}{\eta_{p}}\left(\frac{1}{s h^{C} a a^{c} / b b^{c}+s h^{G} a a^{g} / b b^{g}+s h^{I}}\right),
$$


were $s h^{I}$ and $s h^{C}$ steady state ratios of investment and consumption to output determined as $s h^{I}=\theta \frac{\mu_{I}-\left(1-\delta_{0}\right)}{u r^{k}}$, and $s h^{C}=1-s h^{G}-s h^{I}$, and

$$
\begin{array}{cc}
a a^{c}=1-\frac{b^{c}\left(1-\rho^{c}\right)}{\mu_{z^{*}}-\rho^{c}}, & b b^{c}=1-\frac{b^{c}\left(1-\rho^{c}\right)}{\frac{\mu_{z^{*}}}{\tilde{\beta}}-\rho^{c}}, \\
a a^{g}=1-\frac{b^{g}\left(1-\rho^{g g}\right)}{\mu_{z^{*}}-\rho^{g g}}, & b b^{g}=1-\frac{b^{g}\left(1-\rho^{g g}\right)}{\frac{\mu_{z^{*}}}{\tilde{\beta}}-\rho^{g g}} .
\end{array}
$$

In all models, one can first find the steady state ratios $(k / y)=\theta \mu_{I} /\left(u r^{k}\right),(i / y)=(1-(1-$ $\left.\left.\delta_{0}\right) / \mu_{I}\right)(k / y),(c / y)=1-s^{g}-(i / y)$. Then, in all models except the model with productive government spending,

$$
y=\left(m c\left(\frac{u(k / y)}{h \mu_{I}}\right)^{\theta} h\right)^{1 /(1-\theta)},
$$

and in the model with productive government spending,

$$
y=m c\left(\left(\frac{u(k / y)}{h \mu_{I}}\right)^{\theta} h\left(\frac{\left(1-s^{g c}\right) s h^{G}}{\delta_{0}}\right)^{\alpha_{G}}\right)^{1 /\left(1-\theta-\alpha_{G}\right)}
$$

In all models then, $c, k$, and $i$ can be trivially obtained from their output ratios, $g=s h^{G} y$, and the fixed cost parameter $\vartheta=(1-m c) y$.

Utility parameter $\zeta$ and the lagrangian $\xi$ are different across the models. In the deep habits model:

$$
\zeta=\frac{(1-\sigma)(1-\tau) w(1-h)}{\mu} \frac{1}{c-b^{c} \frac{s^{c}}{\mu_{z^{*}}}}, \quad \text { and } \quad \xi=\left(c-s^{c} \frac{b^{c}}{\mu_{z^{*}}}\right)^{-\sigma} d(1-h)^{\zeta}
$$

where $s^{c}=\frac{\left(1-\rho^{c}\right) c}{1-\rho^{c} / \mu_{z^{*}}}$. (Also, in the deep habits model, $s^{g}=\frac{\left(1-\rho^{g g}\right) g}{1-\rho^{g g} / \mu_{z^{*}}}, \tilde{v}^{c}=\frac{1-m c}{b b^{c}}$, and $\tilde{v}^{g}=\frac{1-m c}{b b^{g}}$.)

For the rule of thumb, productive government spending, and the baseline model,

$$
\zeta=\frac{(1-\sigma)(1-\tau) w(1-h)}{\mu c} \frac{1-\tilde{\beta} \frac{b^{c}}{\mu_{z^{*}}}}{1-\frac{b^{c}}{\mu_{z^{*}}}}, \quad \text { and } \quad \xi=\left(c\left(1-\frac{b^{c}}{\mu_{z^{*}}}\right)\right)^{-\sigma} d(1-h)^{\zeta}\left(1-\tilde{\beta} \frac{b^{c}}{\mu_{z^{*}}}\right) \text {. }
$$

Note that in the rule-of-thumb households, $c^{o}=c^{r}=c$, and $t r^{r}=(1-\tau) w h-c$

In the model with government spending in utility:

$$
\zeta=\frac{(1-\sigma)(1-\tau) w(1-h)}{\mu \tilde{c}}\left(\frac{c}{\tilde{c}}\right)^{-\frac{1}{\nu}} \frac{1-\tilde{\beta} \frac{b^{c}}{\mu_{z^{*}}}}{1-\frac{b^{c}}{\mu_{z^{*}}}}
$$

where

$$
\tilde{c}=\left[\phi c^{(\nu-1) / \nu}+(1-\phi) g^{(\nu-1) / \nu}\right]^{\nu /(\nu-1)}
$$


and

$$
\xi=\phi\left(\frac{c}{\tilde{c}}\right)^{-1 / \nu}\left(\tilde{c}\left(1-\frac{b^{c}}{\mu_{z^{*}}}\right)\right)^{-\sigma} d(1-h)^{\zeta}\left(1-\tilde{\beta} \frac{b^{c}}{\mu_{z^{*}}}\right) .
$$




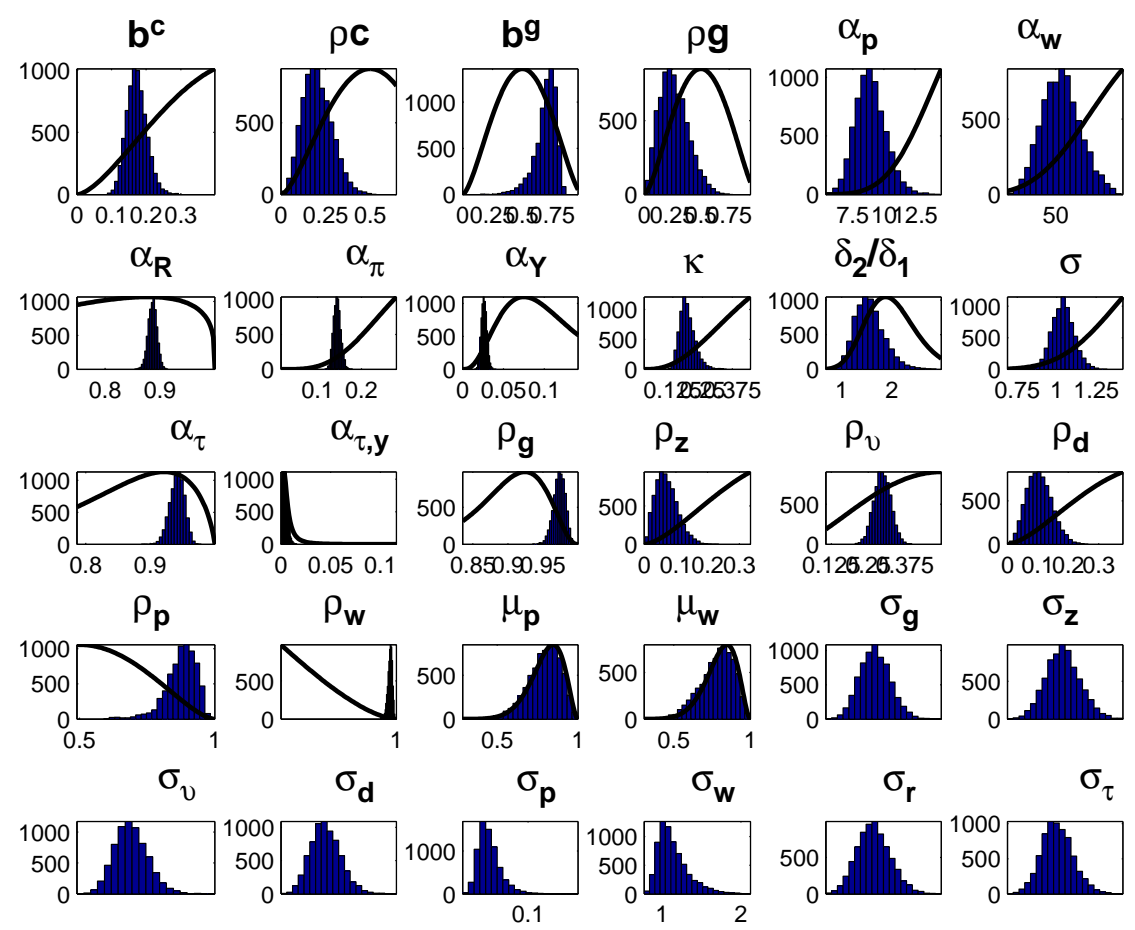

Figure 6: Prior and posterior distributions: Model with deep habits.
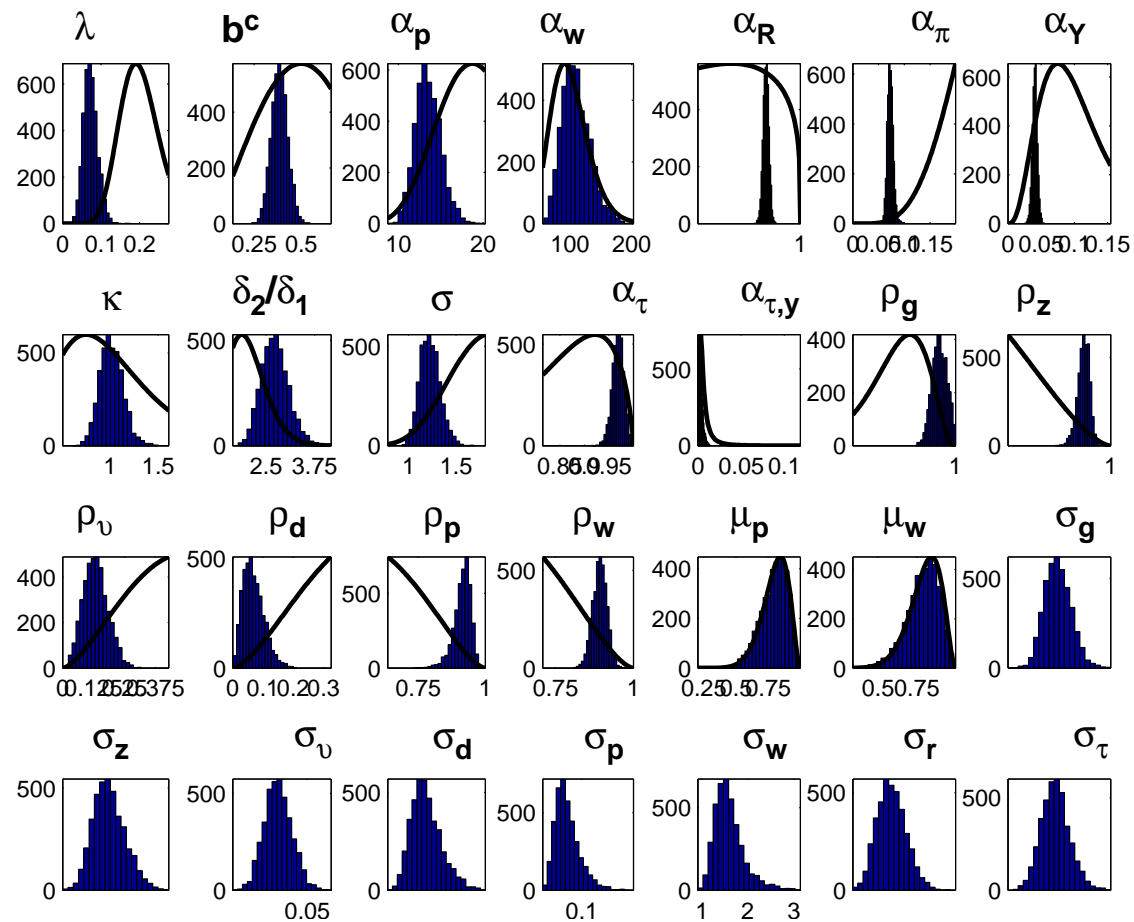

Figure 7: Prior and posterior distributions: Model with rule-ofthumb consumers.

Notes. Black curve is the prior distribution, blue histogram is the posterior distribution. 

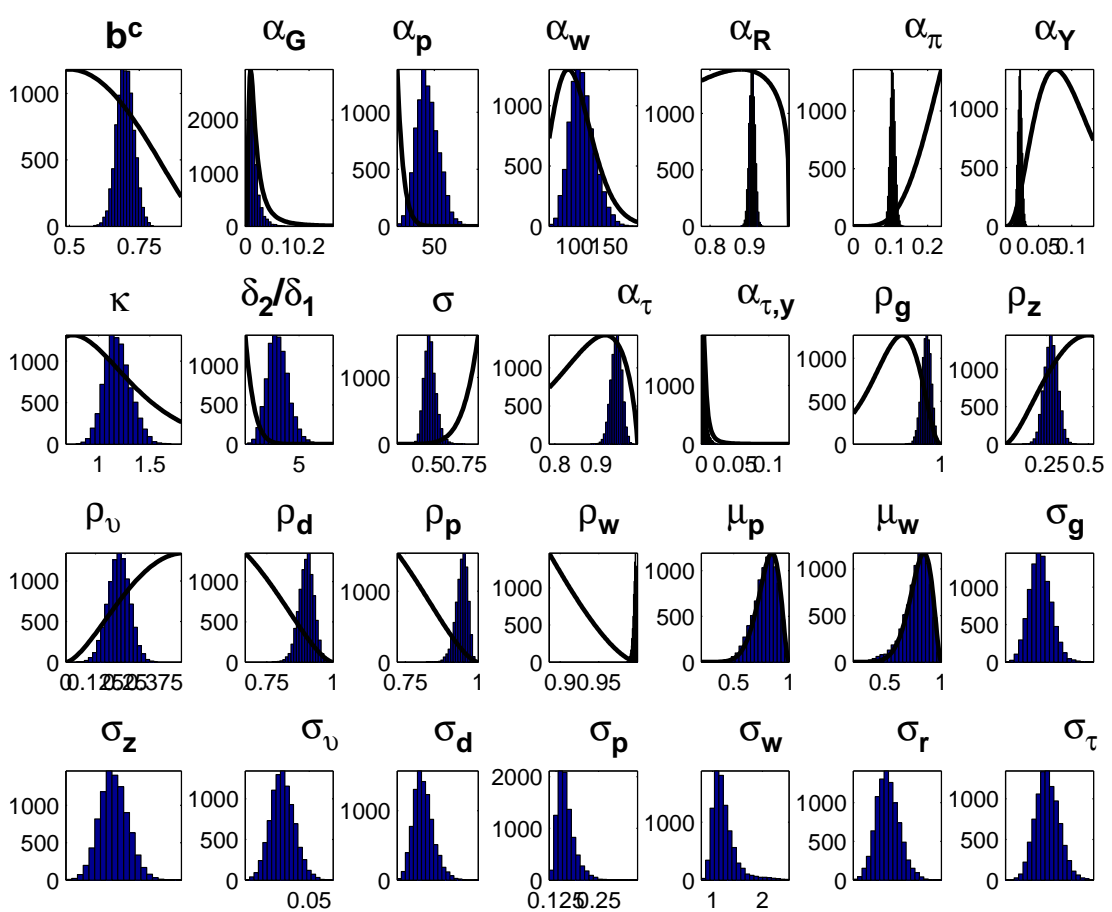

Figure 8: Prior and posterior distributions: Model with productive government spending.
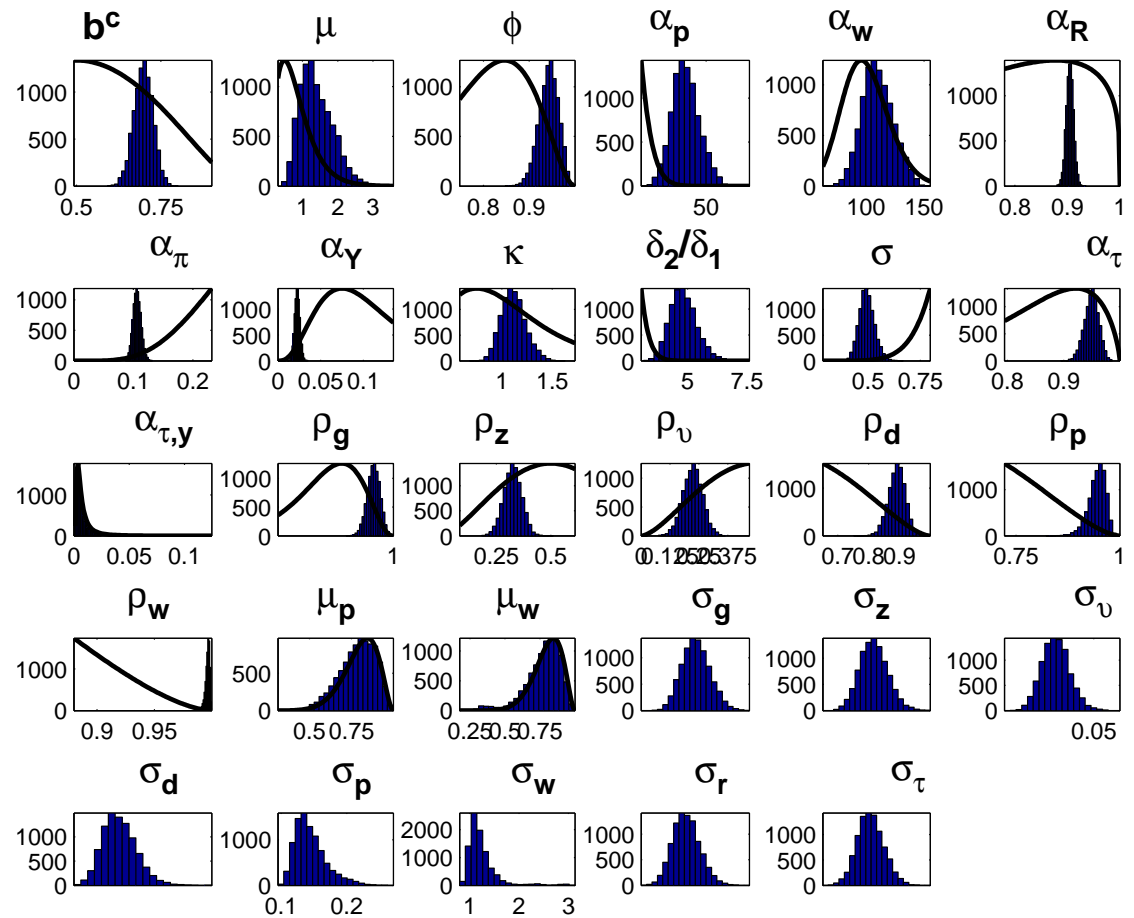

Figure 9: Prior and posterior distributions: Model with government spending in the utility function.

Notes. Black curve is the prior distribution, blue histogram is the posterior distribution. 

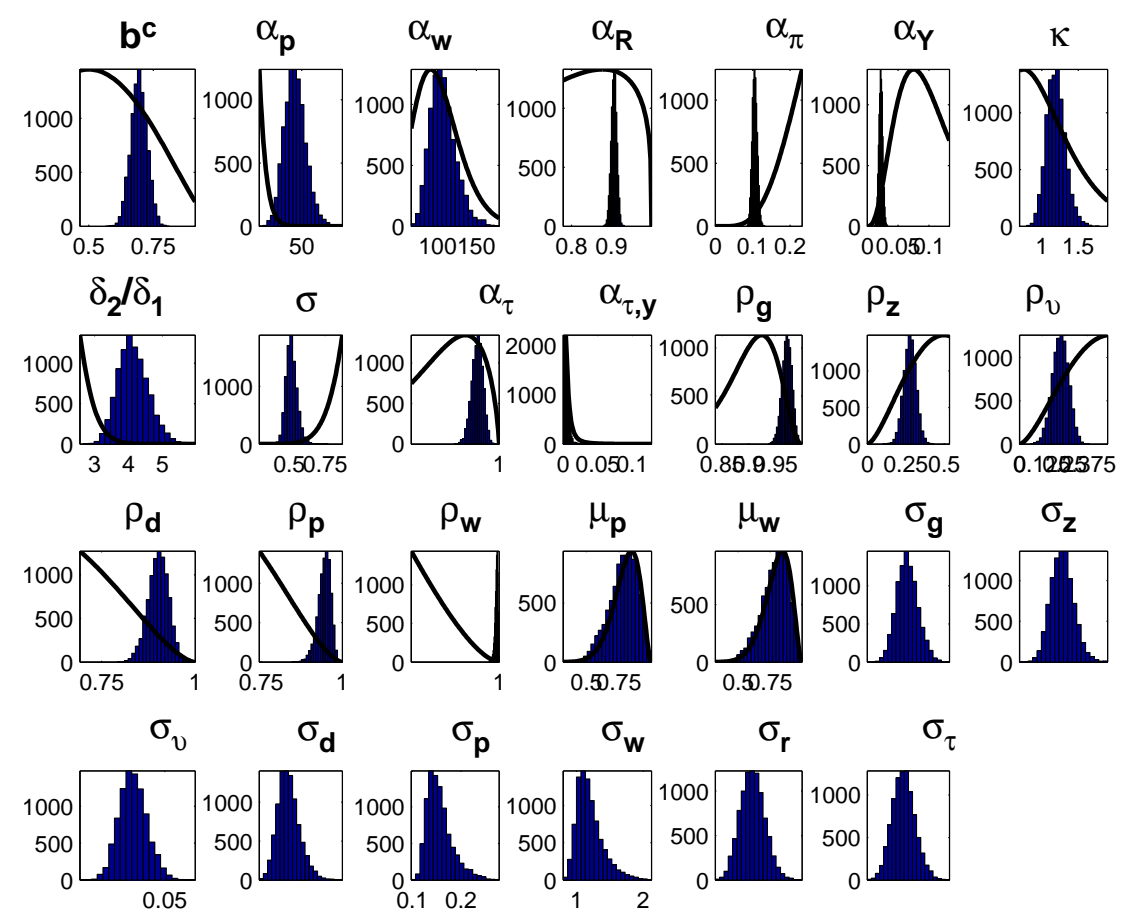

Figure 10: Prior and posterior distributions: Baseline model.

Notes. Black curve is the prior distribution, blue histogram is the posterior distribution. 